\section{El Protorrománico y el Románico en Santiago del Burgo (Zamora). Dos proyectos, una iglesia}

\section{The proto-Romanesque and Romanesque in Santiago del Burgo (Zamora). Two projects, one church}

José IgnaCIO MURILlo Fragero

María de los Ángeles Utrero Agudo

Centro de Ciencias Humanas y Sociales, CSIC. Madrid*

\begin{abstract}
Resumen
Datada a finales del siglo XII, la iglesia de Santiago del Burgo (Zamora) ha sido sometida a una lectura de paramentos que descubre una historia constructiva inédita. Fruto en realidad de dos proyectos constructivos sucesivos, su análisis permite acercarnos a la actividad constructiva de finales del siglo XI y comienzos del XII, momento atrapado entre los estilos protorrománico y románico.
\end{abstract}

Palabras clave: Estratigrafía muraria, Proceso constructivo, Cantería, Marcas de cantero, Convento, Siglos XI-XII.

\begin{abstract}
Dated to the late $12^{\text {th }}$ century, the unknown building history of the church of Santiago del Burgo (Zamora) has been uncovered thanks to the archaeological analysis. This building is actually the result of two buildings projects and its analysis enables to deal with the building activity issue at the end of the $11^{\text {th }}$ and the beginnings of the $12^{\text {th }}$ centuries, period traditionally framed among the proto-Romanesque and the Romanesque styles.
\end{abstract}

Key words: Wall stratigraphy, Building process, Stonecutting, Mason's marks, Convent, $11-12^{\text {th }}$ centuries.

\footnotetext{
*murillo.arq@gmail.com
} utrero@ceh.csic.es

\section{INTRODUCCIÓN}

Santiago del Burgo forma parte del destacado grupo de iglesias románicas que pueblan el casco histórico de la ciudad de Zamora. A diferencia de sus compañeras, la singularidad de una cabecera tripartitita de capillas rectas le ha otorgado un lugar destacado en un conjunto atribuido principalmente y de manera genérica al siglo XII.

De sencilla morfología, el interior de la iglesia se organiza en un aula de tres naves de cuatro tramos y una cabecera tripartita de testero plano, con una capilla central ligeramente avanzada (Fig. 1). La nave principal, de mayor altura, se separa de las laterales por medio de gruesos pilares cruciformes con semicolumnas que sustentan arcos formeros de medio punto y arcos fajones apuntados, ambos doblados. Tanto la cabecera como los tramos originales de la nave central se cubren con bóvedas de cañón, mientras que las naves laterales lo hacen con bóvedas de arista. El edificio se completa con una torre cuadrangular situada en el ángulo suroeste, la cual posee vanos a diferentes alturas para acceder al exterior de las cubiertas.

A primera vista, se observa cómo la iglesia fue testigo del adosamiento en su lado norte de una estancia rectangular, probable sacristía, cuya bóveda de nervios apuntados nos lleva al siglo XVI, así como de un sinfín de estructuras sucesivas, evidenciadas en los numerosos «agujeros» que ocultaron casi todo su perímetro. En fechas tempranas, se introdujeron varios arcosolios, así como otras tantas capillas funerarias ya a lo largo de los siglos XVI y XVII. El retablo principal, de estilo rococó, acoge la representación de Santiago y, junto a otros de carácter menor, completan las adiciones, en este caso muebles, sufridas por el edificio.

Sin embargo, detrás de estas grandes etapas, la secuencia de Santiago del Burgo refleja una historia inédita y rica (Fig. 2) que explica su mencionada singularidad, fruto en realidad de varios proyectos constructivos que han pasado desapercibidos a los ojos de los investigadores. Esta iglesia invita a reflexionar sobre el paso del protorrománico al

\footnotetext{
${ }^{1}$ Este artículo sintetiza el informe arqueológico realizado a raíz de la lectura de paramentos de la iglesia de Santiago del Burgo (Murillo y Utrero 2008). Trabajo encargado por el Servicio de Restauración de la Dirección General de Patrimonio y Bienes Culturales de la Consejería de Cultura y Turismo de la Junta de Castilla y León. Asesor científico: L. Caballero Zoreda (IH, CSIC). Trabajo de campo: L. Caballero Zoreda (IH, CSIC), F. Arce Sainz (IH, CSIC), R. Martín Talaverano (arquitecto, UPM, y tratamiento de planimetría), F. J. Moreno Martín (UCM), J. I. Murillo Fragero (IH, CSIC) y M. ${ }^{a}$ Á. Utrero Agudo (IH, CSIC). Planimetría original: R. Macho Ibáńez y R. Tomillo Alonso (TOPOCAL). Supervisión: H. Larrén Izquierdo (Servicios Territoriales, Zamora, JCyL), M. Gómez Barreiro (Servicio de Restauración, JCyL) y C. Escribano Velasco (Servicio de Restauración, JCyL). Agradecemos la ayuda de L. Peláez Franco, arquitecto responsable del Proyecto de Restauración, y J. Álvarez Esteban, párroco de la iglesia.
} 


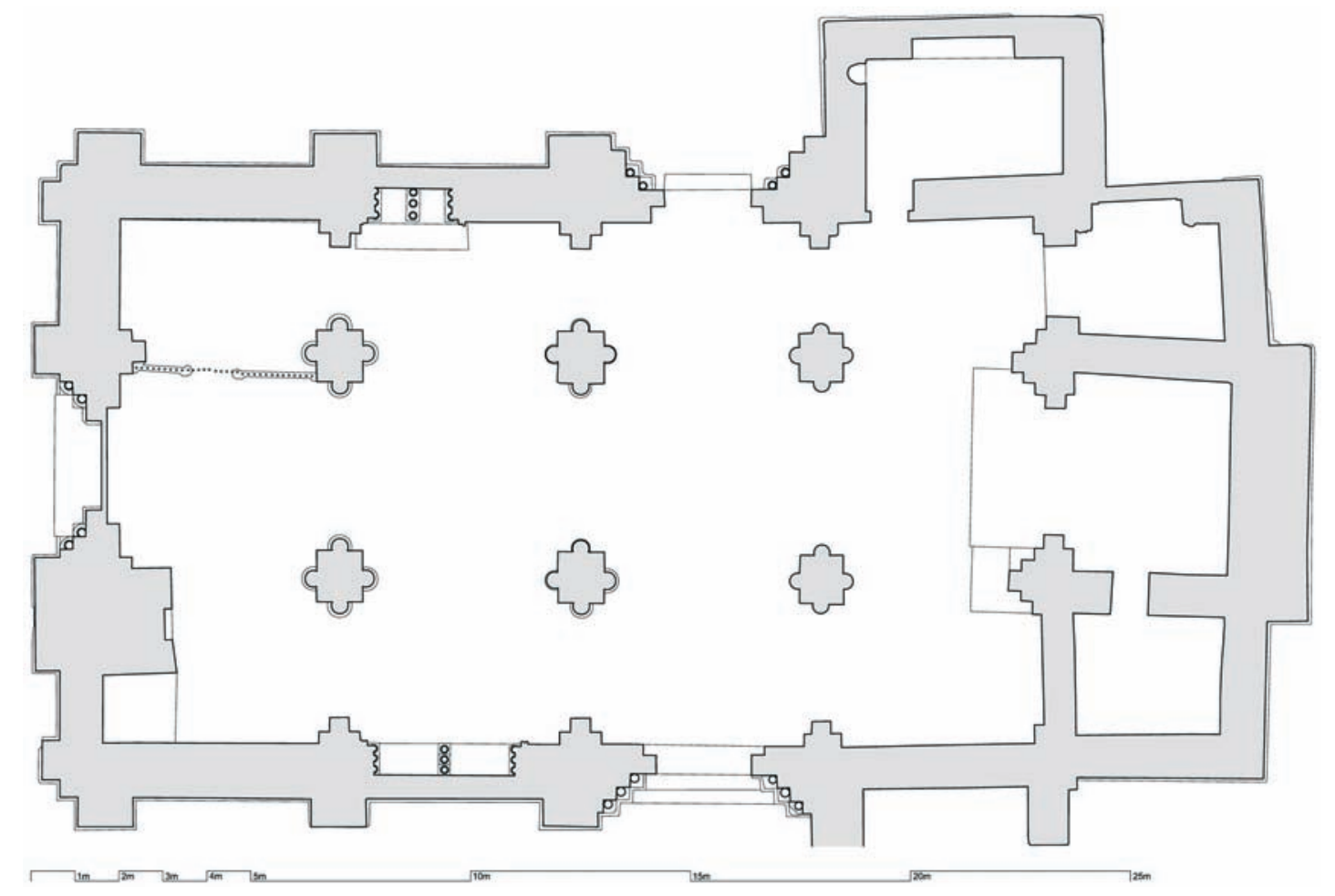

Fig. 1. Planta general de Santiago del Burgo

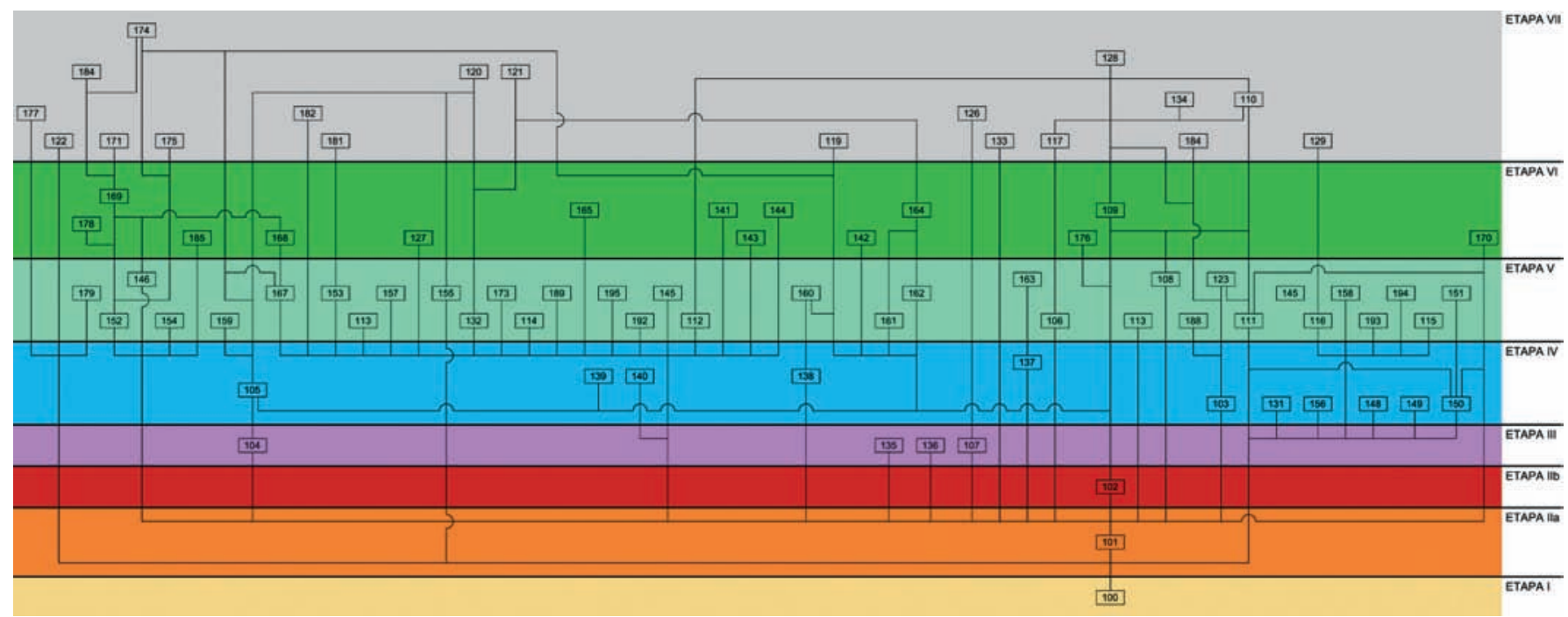

Fig. 2. Diagrama de actividades de Santiago del Burgo

románico, entendidos como periodos que, lejos de reflejar únicamente un cambio tipológico y estilístico, fueron el resultado de un cambio tecnológico destacado, inapreciable en las fuentes escritas, pero guardado por el edificio.

\section{LA CONSTRUCCIÓN DE LA IGLESIA}

La construcción de gran parte de la iglesia que actualmente conservamos (Fig. 3) se debe a la puesta en marcha de dos proyectos sucesivos (Etapas I y II). La Etapa I supone sólo el arranque de la obra desde el Este, es decir, la cabecera y el primer tramo oriental de las naves, anunciando así un proyecto que pretende desarrollar una iglesia de tres naves y triple cabecera, con un eje central destacado en altura y amplitud. La continuación de la construcción hacia los pies forma parte de un siguiente empuje constructivo, probablemente inmediato, perteneciente ya a la Etapa II, durante el cual tiene lugar el alzado del aula, la torre y las cubiertas abovedadas. 


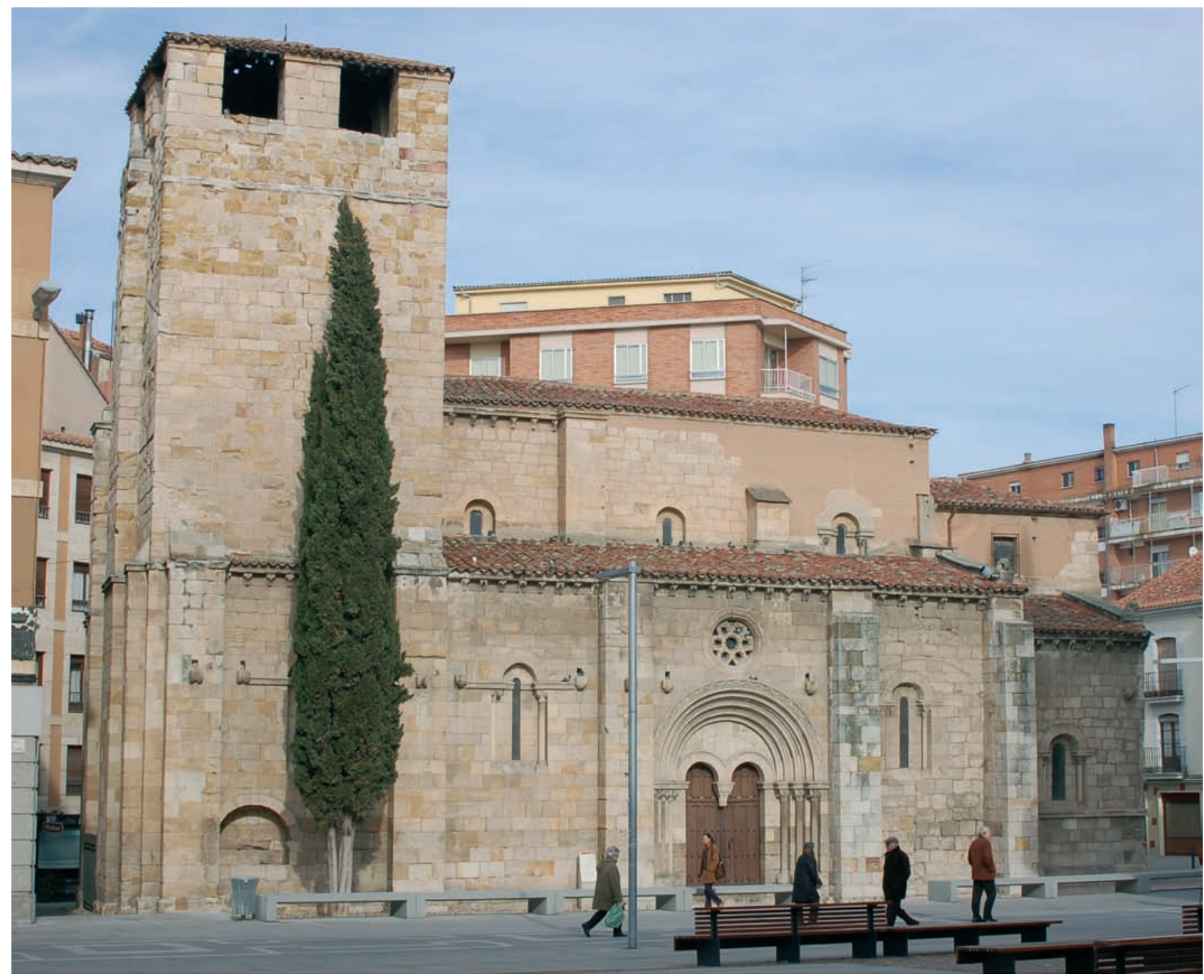

Fig. 3. Imagen general de la iglesia desde el Sur

\section{Etapa I. Edificio primitivo y proyecto original}

La primera obra de la iglesia de Santiago se ejecuta en una fábrica mixta de sillarejo desbastado y sillería escuadrada en las esquinas, vanos y arcos, la cual combina caliza y arenisca. Las hiladas son muy regulares, siendo continuas entre los muros y los pilares. Su altura aproximada es de 30 $\mathrm{cm}$, careciendo de codos, saltos u otro tipo de ajuste entre las piezas. Los sillarejos se disponen según han salido de cantera, es decir, no presentan huellas de talla, siendo su superficie rugosa. La sillería, por el contrario, fue tallada con una herramienta que imprimía incisiones cortas en un ángulo de $45^{\circ}$, pudiendo tratarse de un hacha. Las marcas de cantero son relativamente escasas y de factura sencilla, reduciéndose a leves incisiones que dibujan simples formas poligonales. Gran parte de ellas están concentradas en la primera pareja de pilares cruciformes orientales atribuibles a esta fase y de manera muy esporádica en los muros de las capillas laterales (Fig. 19).

$\mathrm{Al}$ interior, los muros longitudinales de las capillas laterales se alzan en hiladas de sillarejo coronadas por una imposta alta. Otra a media altura recorría originalmente los muros laterales y el testero por debajo de las ventanas de arco de medio punto. Los muros laterales, con un grosor de $0,95 \mathrm{~m}$, absorberían fácilmente los empujes originados por las bóvedas de cañón ligeramente apuntadas, pertenecientes ya a la Etapa IIa (UE 1278 A 101), con una luz reducida a $2,70 \mathrm{~m}$. En la capilla central, los restos de la fábrica primitiva se hallan ocultos por el retablo mayor y afectados por modificaciones y ruinas posteriores, pero la escasa superficie de muro conservado (las enjutas de los arcos interabsidiales, pilares de embocadura hasta la altura de la imposta y ángulos orientales con 


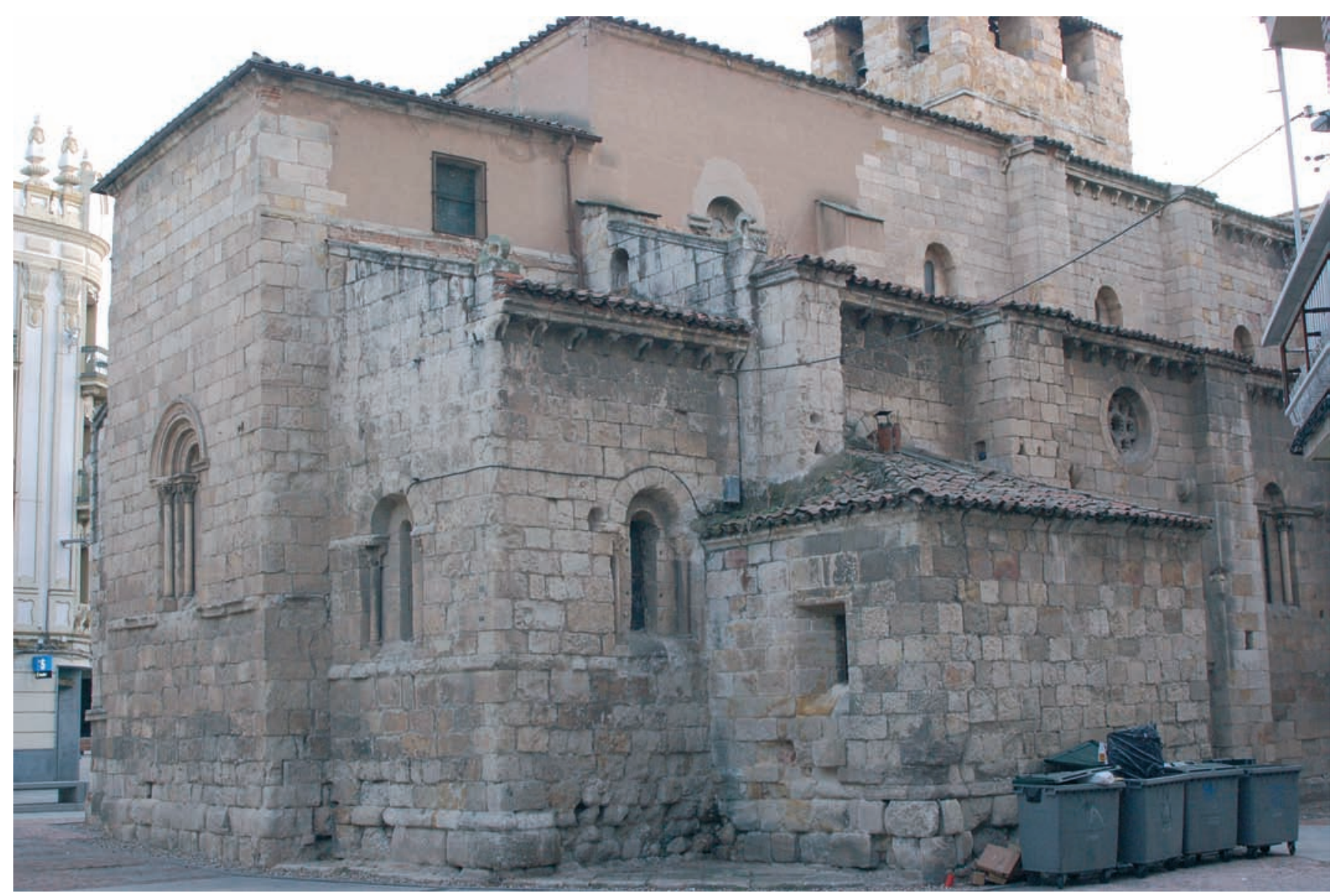

Fig. 4. Exterior del ábside central y septentrional de la iglesia

el testero) corresponde al mismo tipo de fábrica que en las capillas laterales.

$\mathrm{Al}$ exterior, la fábrica de la cabecera (UEs 1000, 1001 1002, A 100) es igual, aunque las hiladas presentan cierta sinuosidad (Fig. 5). De nuevo, los sillarejos se combinan con sillería escuadrada reservada para las esquinas así como las jambas y arcos de las ventanas. Un zócalo biselado y una imposta a media altura marcan el ritmo de los muros. En la capilla norte, el paramento original (UE 1000) incluye las ventanas con arcos de medio punto sobre columnas. El tramo inferior bajo la imposta de la capilla central (UE 1001) y el tramo medio (UE 1002), incluidas las ventanas, de la capilla sur pertenecen a esta obra. Estas cuatro ventanas se rematan con doble arco de medio punto liso, siendo el interior una pieza monolítica y apoyando el exterior dovelado sobre columnillas entregas (Fig. 4).

La obra continúa por el extremo oriental del aula (UE 1143, A 100). En el interior del primer tramo de la nave norte $^{2}$, las hiladas de sillarejo de caras desbastadas se alzan

${ }^{2}$ El paramento exterior de este muro queda oculto por el adosamiento de la capilla funeraria lateral norte en época posterior (UE 1006). hasta la base de la ventana, donde es relevada por la sillería. Esta misma combinación se repite en los pilares laterales que delimitan este tramo. El arco de medio punto de la ventana, descentrada por su proximidad al pilar este, arranca de nuevo sobre una moldura, pero carece de columnas, a diferencia de los arcos de los ábsides. La combinación de sillarejo y sillería se da, por el contrario, en toda la altura del muro sur del mismo tramo. Se repite la forma de la ventana, la cual, en este caso, está descentrada hacia el Oeste. El tramo de la nave central se delimita por los pilares cruciformes de la embocadura del ábside y por la primera pareja de pilares compuestos formados por pilares cuadrados combinados con semicolumnas. El pilar y las cuatro columnas, a excepción de la de la nave central, se unifican con una imposta moldurada.

Los cimientos y basas de esta primera pareja de pilares tienen además diferentes cotas de altura respecto a los siguientes del aula. Su basa se sitúa $0,40 \mathrm{~m}$ por debajo de la tarima actual, mientras que las restantes se sitúan a ras de ella. Por lo tanto, el cuerpo de los pilares orientales es mayor, teniendo que ayudarse de un elevado cimiento- 

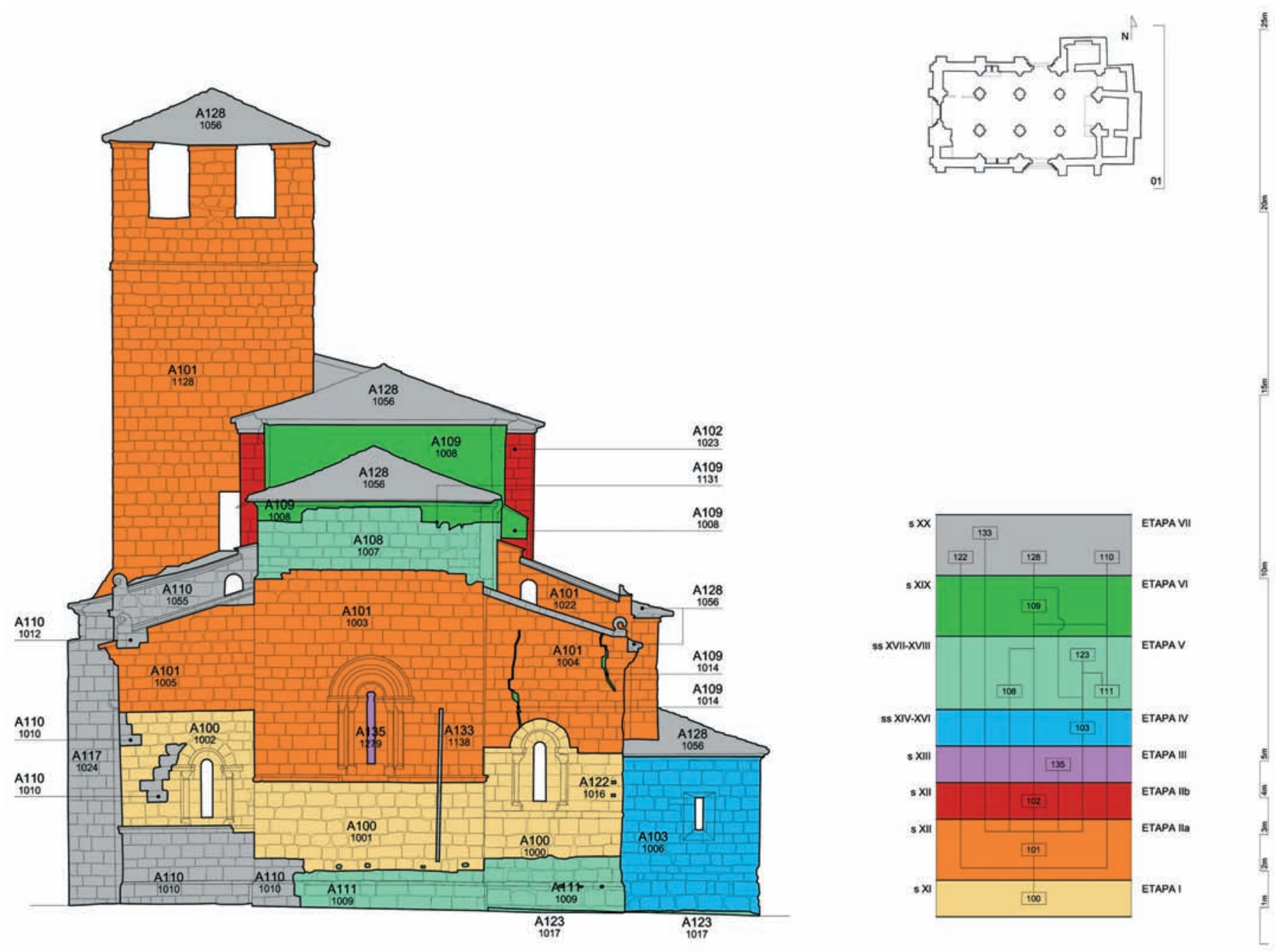

Fig. 5. Plano de UEs y As del alzado este de Santiago del Burgo

podio, el cual, perfectamente tallado, pudo concebirse para ser visto, al menos, en parte (Fig. 6).

\section{De la Etapa I a la Etapa II}

El paso a un segundo momento constructivo se aprecia en un destacado cambio tecnológico y en una clara interfaz (UE 1231, A 100). Esta junta recorre verticalmente los respectivos muros norte y sur del aula en el lado oeste de los pilares occidentales de los primeros tramos orientales (Fig. 7). Se identifica por la presencia de codos, cuñas y saltos de hiladas, recursos que permiten ajustar la obra mixta de sillarejo y sillería de la zona oriental (UE 1143, A 100) con la nueva obra exclusiva de sillería de la zona occidental (UE 1144, A 101). Esta segunda obra se caracteriza además por una imposta que recorre los muros laterales del aula y unos soportes cruciformes con columnas de planta semicircular ultrapasada rematadas con impostas continuas, elementos que no encontramos en la zona este del edificio construida en la Etapa I.
En el muro sur del primer tramo oriental, la construcción en sillarejo de toda la altura del muro, incluyendo el tímpano, podría hacer pensar que su bóveda de aristas también pertenecería a la Etapa I, dado que no se aprecian cortes en el tímpano. Sin embargo, en el tramo norte correspondiente, la clara diferencia entre el sillarejo de la parte baja y la sillería de la parte alta, cuyo tímpano también se une a la bóveda de aristas, y la presencia de un salto en las hiladas de sillería a una altura próxima al extremo superior de la solución de continuidad UE 1231 indicaría su pertenencia a la Etapa II. En el muro sur, el guardapolvo oculta gran parte de esta junta, pero aun así se aprecia como en la parte baja corresponde con la jamba oriental de la puerta.

Por lo tanto, únicamente esta interfaz vertical (UE 1231) y los cambios tecnológicos (ausencia o presencia de marcas de cantero, huellas de talla, sillarejo frente a sillería) y formales (tipos y disposición de molduras y pilares) permiten constatar la interrupción de una obra que, cuando se retomó, empleó otro lenguaje. 


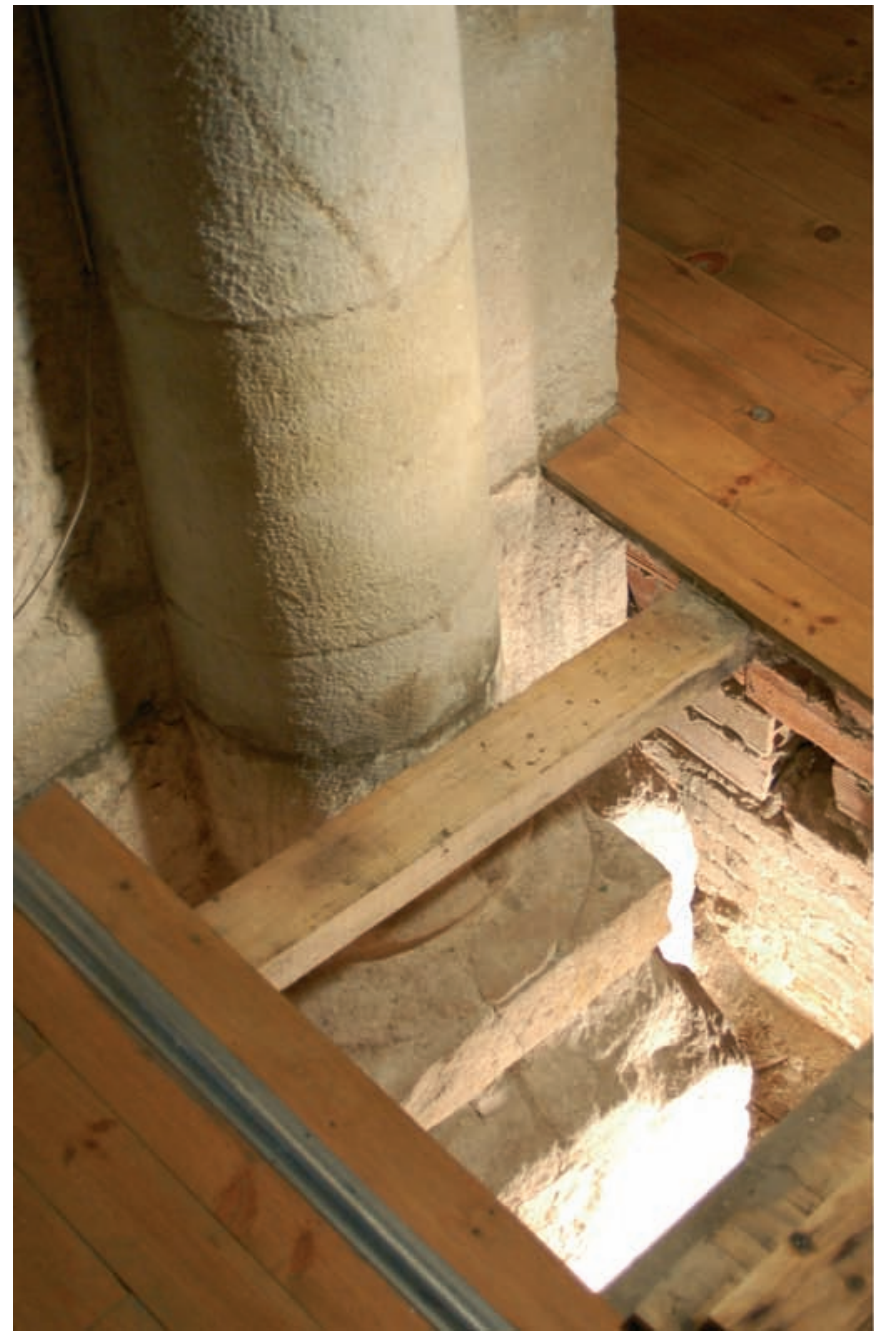

Fig. 6. Basa del primer y segundo pilar de la arquería septentrional de la iglesia

\section{Etapa Ila. Inicio del Segundo Proyecto, Etapa de Obra 1}

La fábrica de la Etapa II se define por unas características muy claras frente a la anterior. Las hiladas de sillería son regulares y horizontales, continuas entre muros y pilares, prescinden de ajustes y pierden la sinuosidad de la obra previa. Alternan sus alturas, con módulos en torno a los $0,30 \mathrm{~m}$ y a los $0,40 \mathrm{~m}$. A diferencia de la Etapa I, los muros se alzan exclusivamente en sillería caliza bien escuadrada, cogida con mortero de cal en finas juntas y tallada con una herramienta, posiblemente un hacha, de hoja larga $(65$ $\mathrm{mm}$ ) y recta, aplicada a intervalos pequeños (en torno 70$100 \mathrm{~mm}$ ) en un ángulo de $45^{\circ}$. Estas huellas de talla no pasan de un sillar a otro, por lo que las piezas fueron acabadas antes de ser colocadas en el muro. Una imposta perimetral recorre todo el interior del aula desde el primer tramo oriental, unificando sus muros y los pilares de las arquerías, cuya planta cruciforme es el resultado de la

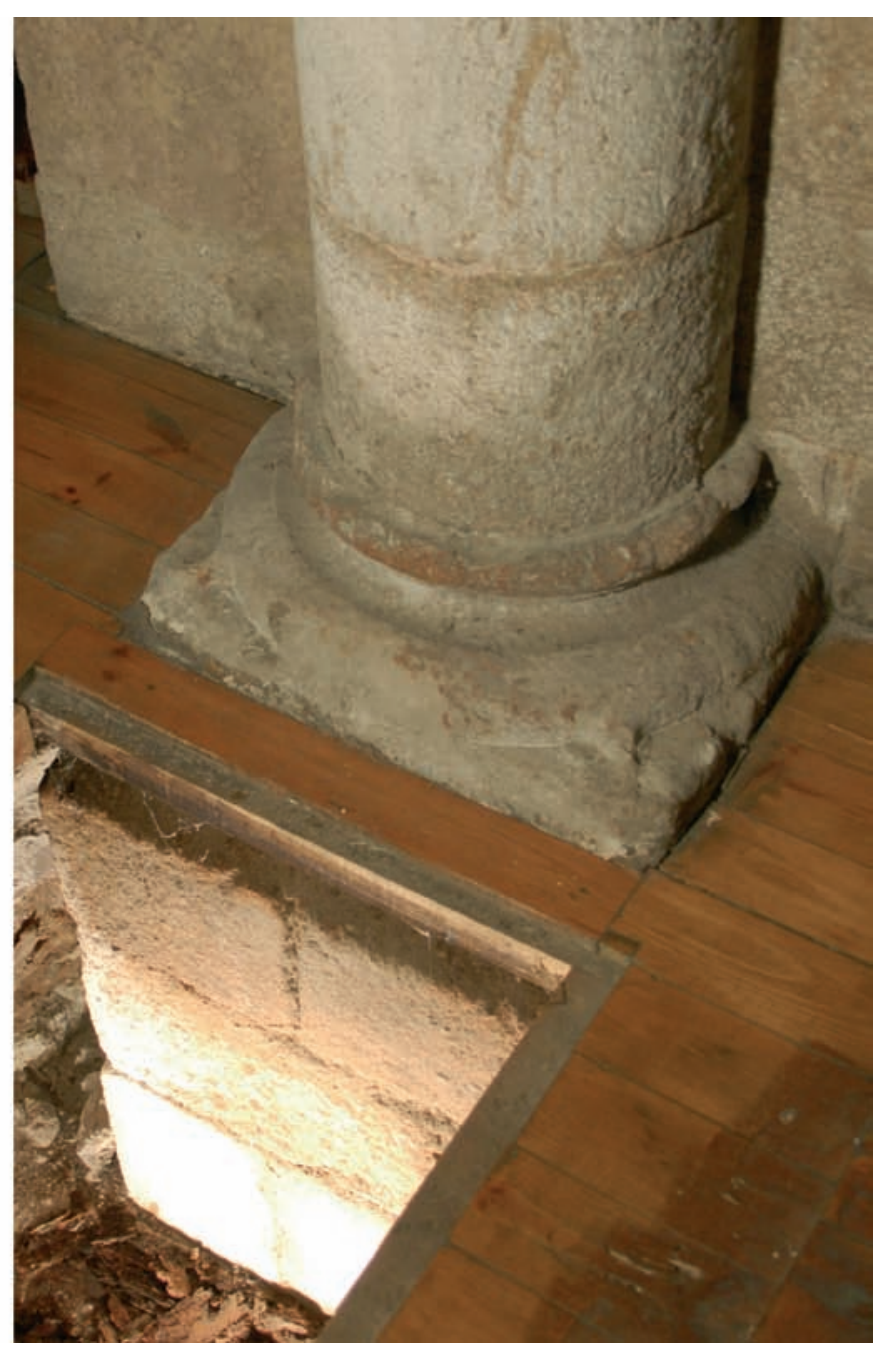

unión de pilares cuadrados con cuatro semicolumnas de planta ultrasemicircular, todo ello unificado con una imposta continua. Por el contrario, recordamos que el primer pilar oriental de la Etapa I se distingue por la planta semicircular de las columnas y la carencia de imposta en la pareja ubicada en el lado de la nave central, así como por una diferencia de nivel de $0,40 \mathrm{~m}$ respecto a los de la Etapa IIa. Las arquerías son siempre dobles, con arcos paralelos y adosados el uno al otro.

Pero la novedad más destacada de la fábrica de la Etapa II es la abundante presencia de marcas de cantero dispersas por todo el edificio, siendo más numerosas al interior ${ }^{3}$. Estos signos aumentan en número, tipos y tamaño. Su talla se hace más profunda y señalada, recrean-

\footnotetext{
3 Se debe tener en cuenta que la distancia y altura de los paramentos exteriores dificulta su observación, lo que junto a su natural exposición a los agentes meteorológicos influye en su documentación.
} 

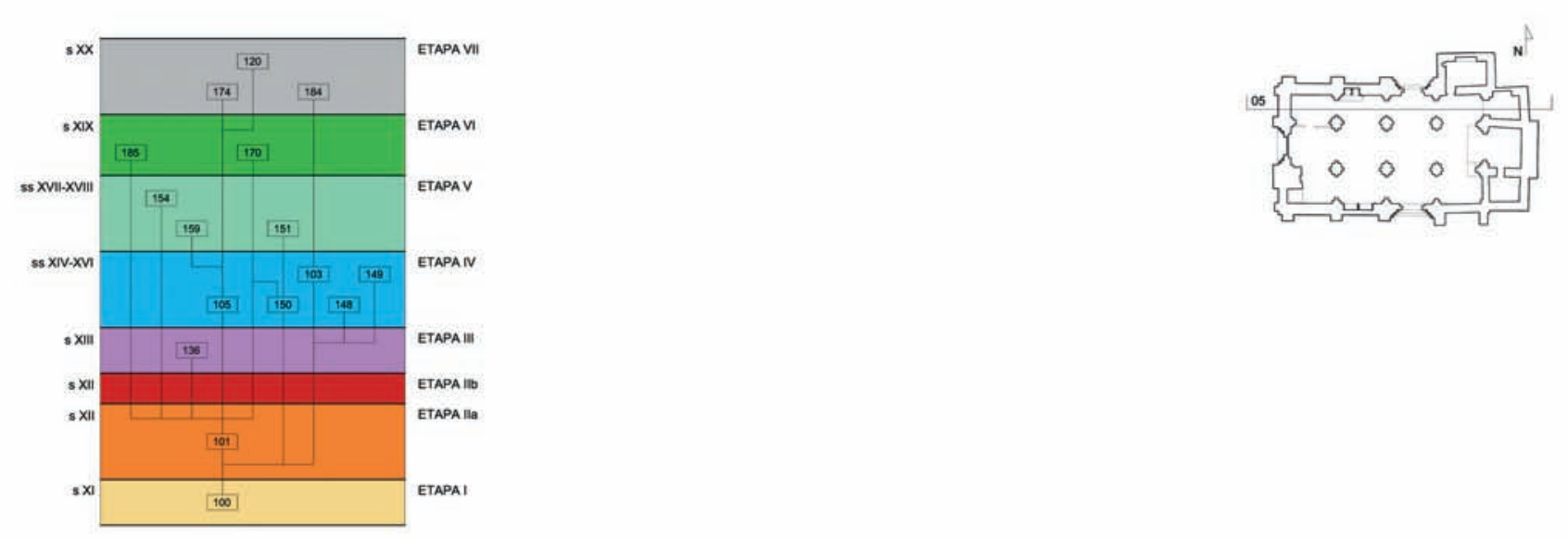

Fig. 7. Plano de UEs y As de la sección norte de Santiago del Burgo

do formas que han pasado de los sencillos polígonos de la Etapa I a motivos letrados e iconográficos presentes de manera copiosa tanto en los muros como en los pilares de la arquería (Fig. 19).

La cabecera de la Etapa I es ahora realzada y cubierta. Las capillas laterales se dotan de bóvedas de medio cañón de perfil apuntado (UE 1278, A 101) y los paramentos exteriores son recrecidos (UEs 10031004 1005, A 101). La ventana de la cabecera central (UE 1003) se hace más rica, con un arco de triple arquivolta y guardapolvo sobre dos parejas de columnillas ${ }^{4}$. Los respectivos frentes norte y sur de las capillas (UEs 1004 1005) se rematan con cornisas sobre modillones (Fig. 5).

El mismo fenómeno se constata en el aula (Fig. 7), cuyos muros norte (UE 1143, A 100) y sur (UE 1018, A

\footnotetext{
${ }^{4}$ Tipológicamente similar a los ejemplos de otras iglesias zamoranas, como las de San Ildefonso, Santa María la Nueva, San Esteban y San Juan de Puerta Nueva.
}

100) del primer tramo oriental son realzados (UEs 1004 1144 1019, A 101), hecho que despeja las dudas previas sobre las bóvedas de aristas, las cuales pertenecen según esta secuencia a la Etapa IIa. La construcción del aula continúa desde estos tramos hacia el Oeste (UEs 1022 1144, A 101; Fig. 10). Se realizan las naves laterales completas y la central hasta la altura de sus impostas medias, dejando para un segundo momento (Etapa IIb) su coronamiento con los muros altos de los tramos centrales y las bóvedas de la nave principal (Fig. 8).

Se abren dos vanos enfrentados en el segundo tramo de las naves laterales desde el Este. Ambos se componen al interior de un arco rebajado apuntado que abraza otro menor de medio punto (Fig. 7). Sobre ellos se abre un rosetón adovelado abocinado de doble celosía. Los tramos siguientes se iluminan con ventanas de arco de medio punto con imposta continua con el muro y con jambas rectas al interior y abocinadas al exterior. Un tercer vano de acceso se abre en la fachada oeste, del mismo tipo, pero de 


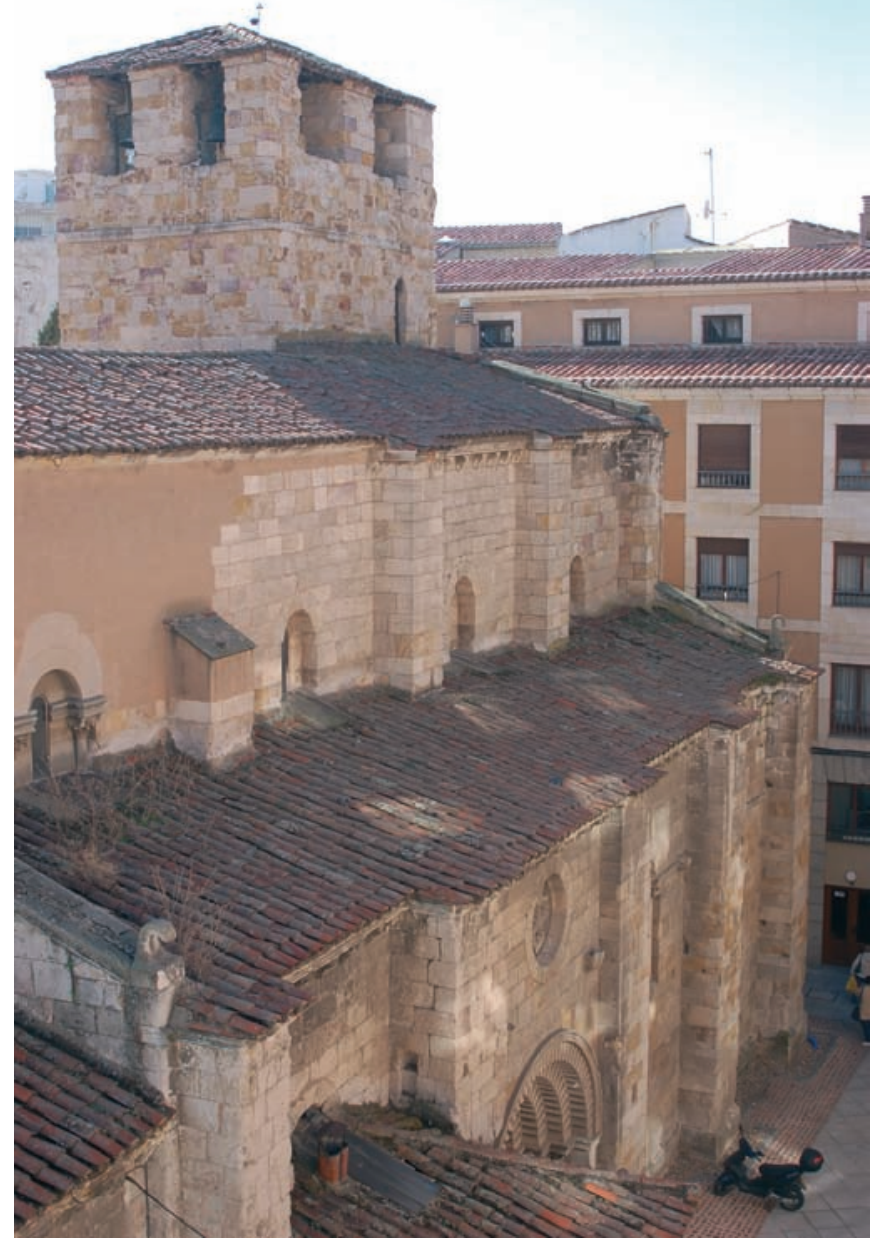

Fig. 8. Exterior de los tramos occidentales superiores de la iglesia y su torre desde el Norte

mayor tamaño. Es de destacar cómo la imposta perimetral se ajusta a su trasdós apuntado, ayudando así a unificar la parte baja de la iglesia. Sobre esta puerta se abren dos ventanas en la zona media y un rosetón, también de doble celosía, en la zona alta.

$\mathrm{Al}$ exterior, estos vanos son portadas finamente decoradas y enmarcadas por contrafuertes (Fig. 9). La portada sur posee tres arquivoltas molduradas y un rosetón superior que se ajusta a su trasdós. En la portada oeste destacan las dovelas lobuladas, mientras que en la norte son almohadilladas $^{5}$. Dos hiladas y media separan el trasdós de su arco de la base de otro rosetón, diferencia que ayuda a mantener al interior las mismas cotas de estos elementos decorativos entre naves de distinta altura.

Mención aparte merece el único tímpano de la iglesia, situado en la portada sur (UE 1025, A 101). La

5 Gómez Moreno $(1927,151)$ describe la policromía de esta portada, hoy perdida. Aún se aprecian restos de pintura negra en la portada sur y roja en la norte.
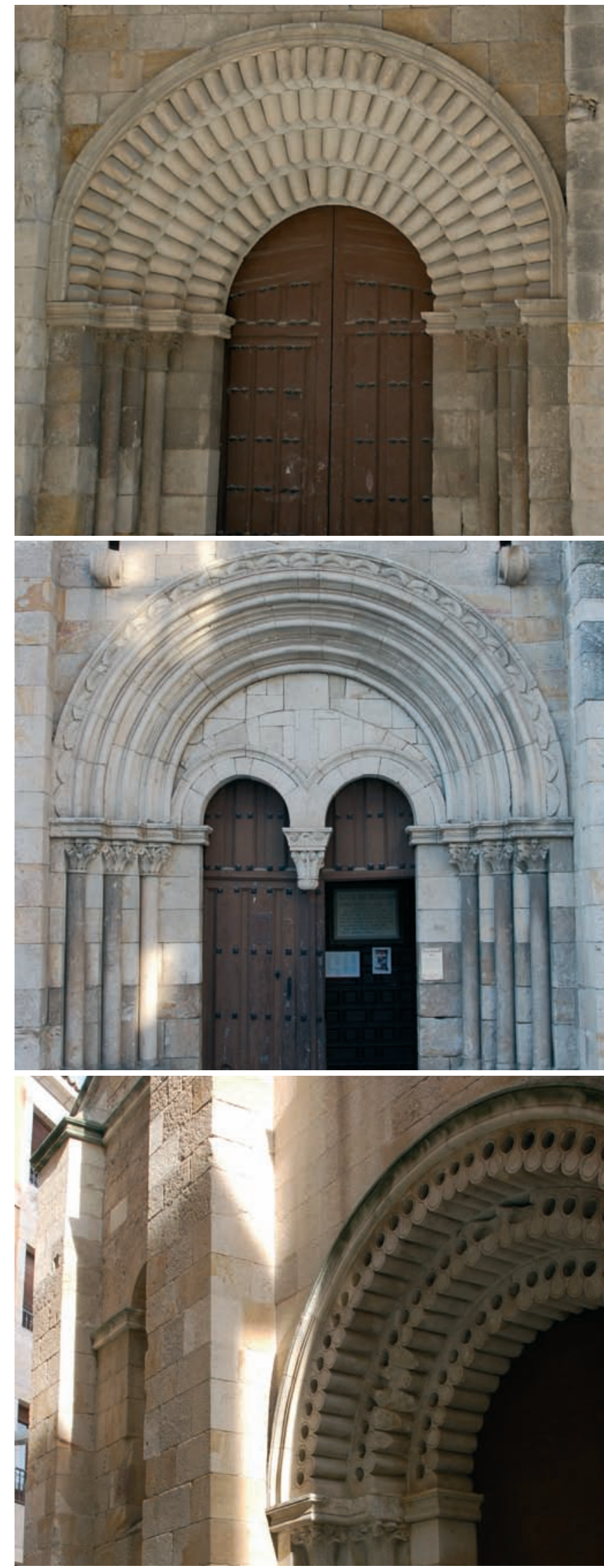

Fig. 9. Portadas septentrional, meridional y occidental de la iglesia 


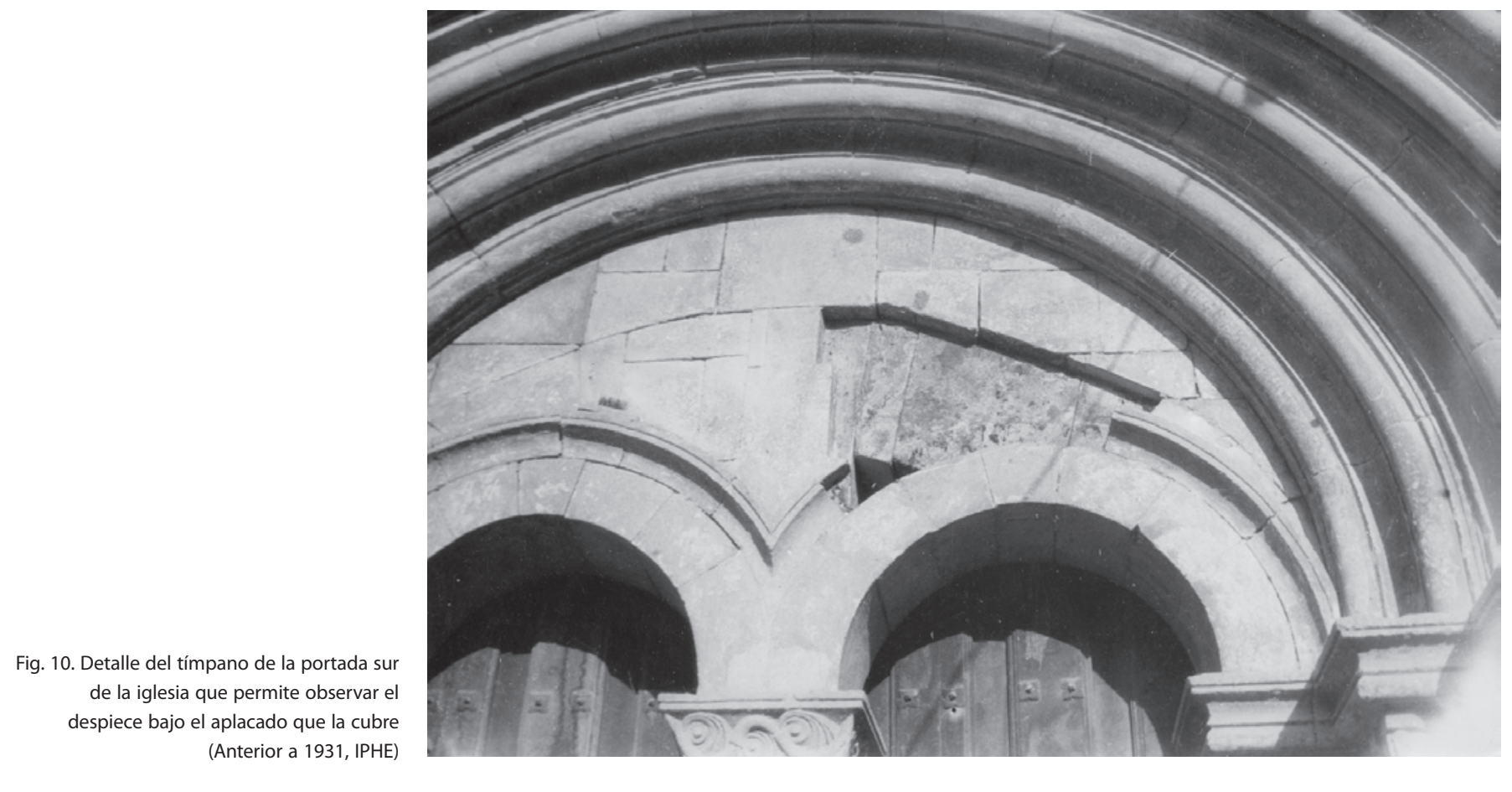

fábrica del tímpano tiene un despiece irregular de sillares que se ajustan a su forma mediante juntas rectas unidas con mortero. Es liso y su límite inferior está ocupado por dos arcos de doble rosca de medio punto geminados. Sus arranques coincidentes dan paso a una clave pinjante que reproduce un cimacio y un capitel decorado con motivos vegetales, pero sin columna de soporte $^{6}$. Este tipo de despiece no asegura la estabilidad del tímpano, pero ignoramos la unión real de las piezas, pudiendo haber algún tipo de despiece oculto y/o anclaje interior que sea el responsable de la unión de los sillares ${ }^{7}$. La documentación fotográfica (anterior al año 1931) muestra el elemento descrito como un chapado de un tímpano interior con un arco de brazos rectos y una clave prolongada, la cual termina en el pinjante mencionado (Fig. 10).

La fachada oeste de la iglesia (UE 1133, A 101) también se realiza en este momento. La zona alta del paramento es equivalente a la descrita para la zona bajo la imposta (UE 1022, A 101), sobre la cual se alzan los vanos vistos al interior, con tímpano monolíticos lisos y doble arquivolta, y el rosetón. El cuerpo de la torre prescinde de huecos de iluminación en su parte baja, no así la parte correspondiente a la nave norte simétrica, con una ventana sencilla de doble arco liso sobre moldura.

6 Como elemento «rarísimo» del siglo XII para Gómez Moreno (1927, 150). Gudiol y Gaya $(1948,277)$ consideran que es posterior, aunque no ofrecen sus argumentos.
A diferencia de los arcos de medio punto de la arquería, los arcos diafragma de las naves laterales son también dobles, pero ligeramente apuntados. Descansan respectivamente sobre las columnas de los pilares cruciformes de las arquerías de las naves y sobre los pilares de los muros perimetrales del aula, creando un total de cuatro tramos. Al exterior se corresponden con contrafuertes prismáticos enjarjados con el muro. Estos arcos sostienen bóvedas de aristas construidas en dovelas rectangulares calizas. Todos los tramos son equivalentes, a excepción del tramo suroeste, cuya bóveda debe adaptarse a un tramo más corto por la presencia de la torre (Fig. 11).

En este mismo tramo suroeste, están las huellas de un espacio menor abovedado desmontado (UE 1254, A 162). Su bóveda de medio cañón, con eje Este-Oeste, se prolongaba hasta 3,21 m. Arrancaba sobre el mismo muro sur del aula, en el cual se conserva el arranque degollado, y un muro norte exento, ahora también eliminado, de $0,76 \mathrm{~m}$ de grosor, creándose así una cámara de $1,58 \mathrm{~m}$ de ancho. El trasdós de la bóveda servía de apoyo a un suelo horizontal situado a la altura del alfeizar de la ventana y de la puerta oriental alta de la torre, creando una especie de tribuna alta de función desconocida (Fig. 12).

El cuerpo inferior de la torre ${ }^{8}$ (UE 1022, A 101) es completamente solidario con los muros sur y oeste del aula,

\footnotetext{
Gómez Moreno (1927, 150-51) asegura que debe formar cuerpo con el arco, siendo un único elemento.

${ }^{8}$ La lectura del interior de la torre no se ha realizado por falta de planimetría.
} 

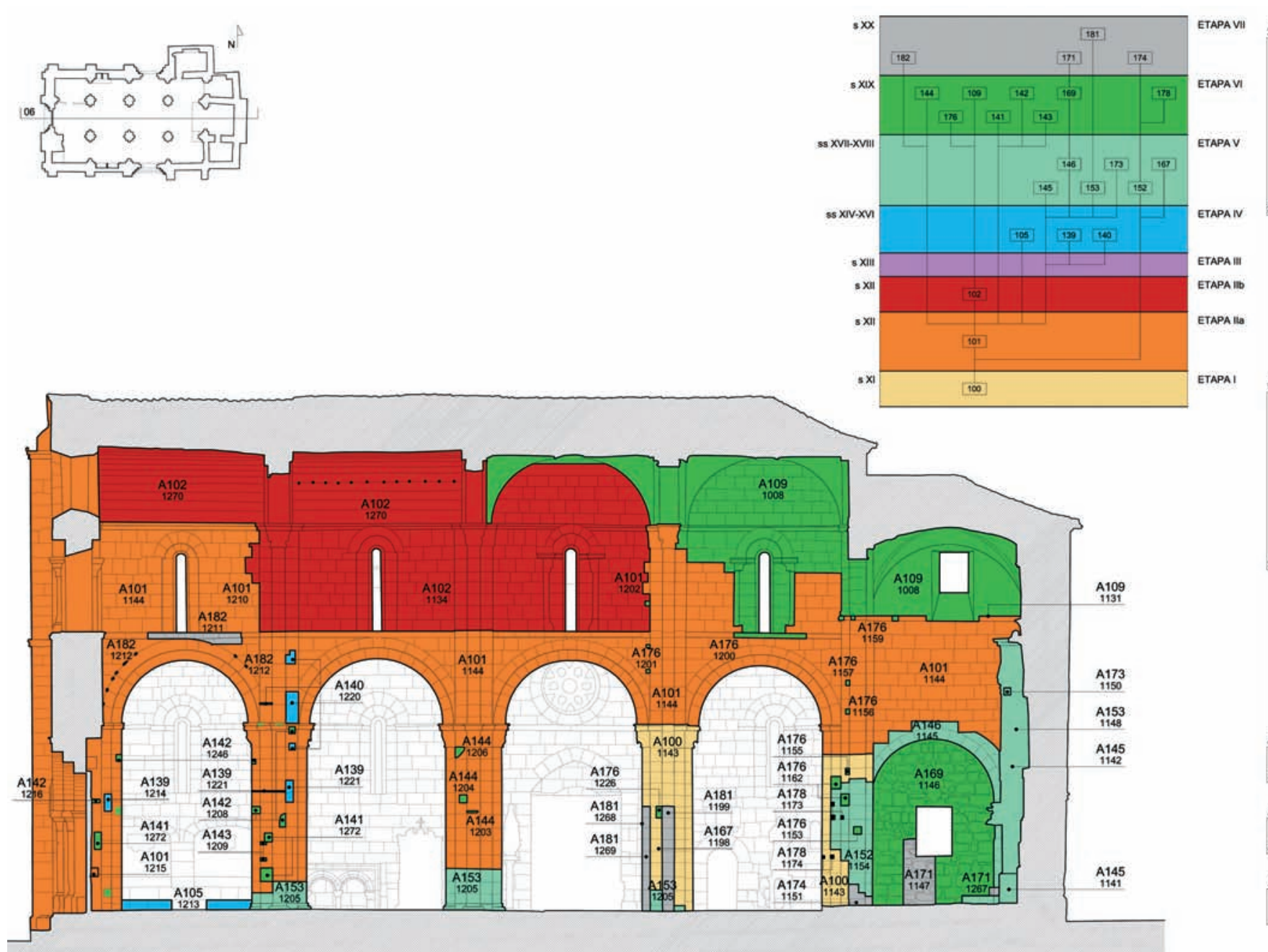

Fig. 11. Plano de UEs y As de la arquería norte de Santiago del Burgo

siendo de hecho la misma unidad (Fig. 13). El cuerpo superior (UE 1128, A 101), a partir de la imposta baja, se ejecuta en la misma sillería, aunque se aprecia una mayor combinación de calizas. Los merlones orientales, los únicos posiblemente originales de este momento, generaron vanos arcuados. Hoy se encuentran degollados y sus jambas sirven de asiento a la cubierta'. En la cara oriental de la torre se abre un vano adintelado de acceso a la cubierta. En la occidental, dos aspilleras iluminan la escalera y un vano a modo de nicho (UE 1057, A 101) decora el tramo entre contrafuertes.

Finalmente, la serie de ménsulas (UE 1022, A 101) de los muros norte y sur del aula evidencian la presencia original de dos pórticos que cobijarían las entradas. Estas ménsulas soportarían el peso de los durmientes de madera, cuyos extremos exteriores debieron ayudarse de pies derechos (Fig. 13).

9 Hecho observado también por Gómez-Villaboa $(1912,22)$, quien considera por ello que la torre no fue acabada.

\section{De la Etapa lla a la Etapa llb}

Por lo tanto, esta Etapa IIa significa la construcción de todo el perímetro murario del aula, incluyendo la parte baja de la torre y las arquerías, los vanos de acceso y de iluminación, así como los rosetones y las bóvedas de aristas de las naves laterales.

Sin embargo, la iglesia es el fruto de un proceso constructivo, cuyas fases dan lugar a la creación de juntas de obra que, lejos de reflejar etapas históricas, constituyen la guía para reconstruir ese proceso. Mientras que la junta UE 1231 (A 100) diferencia la Etapa I de la II, pues responde a un cambio tecnológico y forma ${ }^{10}$, las juntas UEs 120212101222 (A 101) dan testimonio del avance constructivo del edificio. Se trata de puntos de unión entre los distintos esfuerzos y/o cuadrillas constructivas que se manejan, sin embargo, con el mismo lenguaje técnico y formal. La UE 1202 se sitúa en los muros altos de la nave

\footnotetext{
${ }^{10}$ Ver descripción en Etapa I.
} 


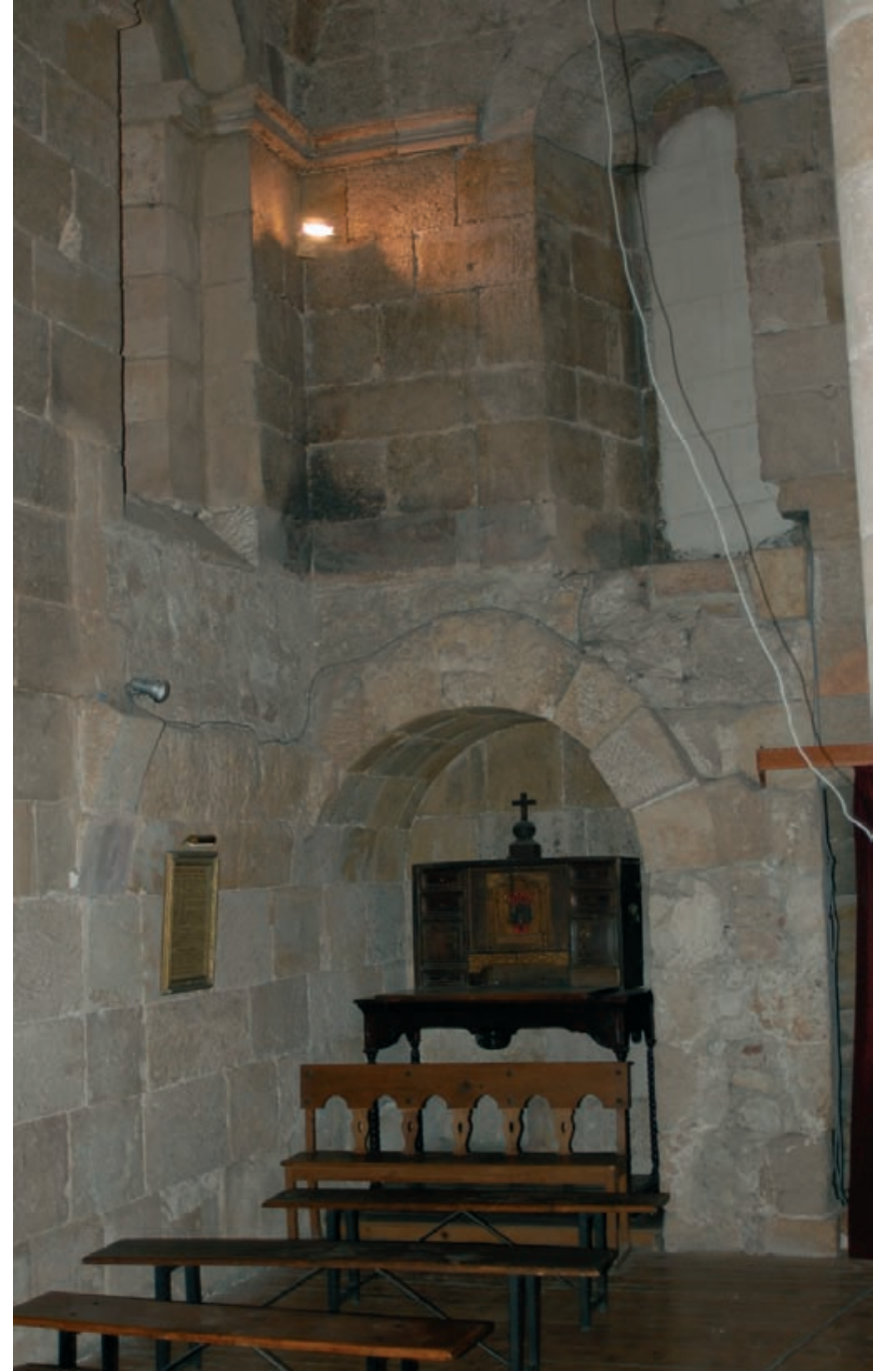

Fig. 12. Zona abovedada a los pies de la iglesia

central (Fig. 11). Se ajusta verticalmente a los ángulos occidentales de la primera pareja de pilares cruciformes de la arquería (segundo tramo desde el Este), identificándose por el salto de hiladas entre pilares y muro contiguo hacia el Oeste. Las UEs 12101222 se encuentran enfrentadas en los mismos muros de la nave central junto a los ángulos occidentales de la última pareja de pilares de la arquería y se identifican por el mismo salto de hiladas (Fig. 11). Las juntas horizontales suelen coincidir con las impostas, por lo que su individualización forma parte de la interpretación que se desprende de las clarísimas juntas verticales. En este sentido, es posible que las bóvedas de medio cañón apuntadas de los ábsides laterales puedan pertenecer también a este momento. Ambas se realizaron en hiladas horizontales de sillares largos de caliza, siendo equiparables al exterior con el realzado (UEs 1004 1005, A 101) de los muros originales (UEs 1000 1002, A 100), lo que las sitúa definitivamente en esta etapa. En la cabecera central, la ruina posterior nos ha privado de conocer el tipo de cubierta, pero se establece la misma secuencia de recrecimiento (UE 1003, A 101) del muro primitivo (UE 1001, A 100).

\section{Etapa Ilb. Finalización del Segundo Proyecto, Etapa de Obra 2}

Entre la UE 1202 (A 101), por un lado, y las UEs 1210 y 1222 (A 101), por otro, discurren los muros altos de la nave central, sobre los cuales se alzan las bóvedas con sus arcos fajones. Todo ello forma ya parte de la Etapa IIb. Es decir, una vez realizada la parte baja del aula y sus bóvedas laterales de aristas (Etapa IIa), así como todo el testero occidental, el edificio está preparado para ser rematado en altura (Etapa IIb).

Su fábrica es idéntica a la descrita para la Etapa IIa. Tanto el muro sur (UE 1023, A 102) como el norte (UE 1134 A 102), así como las bóvedas que sostienen (UE 1270, A 102) y rematan el edificio iniciado en las etapas previas, se refuerzan con contrafuertes entre los cuales se abren ventanas con arcos dobles de medio punto. En las ventanas del muro sur (UE 1023), las claves de los arcos han descendido ligeramente y se han agrietado. Estos movimientos fueron ocasionados seguramente por la ruina del extremo este de la nave y de la cabecera centrales (UE 1131, A 109, Etapa VI). De las cinco ventanas altas originales conservadas, cabe destacar que su factura es simétrica por tramos, al menos en las dos parejas de los tramos centrales, produciéndose la misma alternancia de columnas e impostas en ambos muros. Arrancan de la línea media de imposta y ajustan sus arcos a la superior. Ambos muros altos se coronan al exterior con una cornisa sobre modillones.

A diferencia de estas grietas de movimiento, las fisuras marcadas en el muro oeste de la iglesia (UE 1219, A 102) responden al asentamiento y puesta en carga del edificio. Se originan en los ángulos de encuentro de los tercios inferiores de la bóveda y el testero y continúan en la zona central de las ventanas del tramo medio del muro, arrastradas por la trabazón de los paramentos. Un motivo similar pudo tener la irregularidad de la junta de la cuarta hilada de la bóveda occidental en su brazo meridional (UE 1223, A 147). En este caso, la presión ejercida por el muro norte de la torre, cuya carga recae directamente sobre este punto, pudo provocar el estallido de la fábrica.

Las dos bóvedas de cañón occidentales conservadas (UE 1270, A 102) se componen de hiladas regulares horizontales de sillares calizos largos. Presentan los agrieta- 


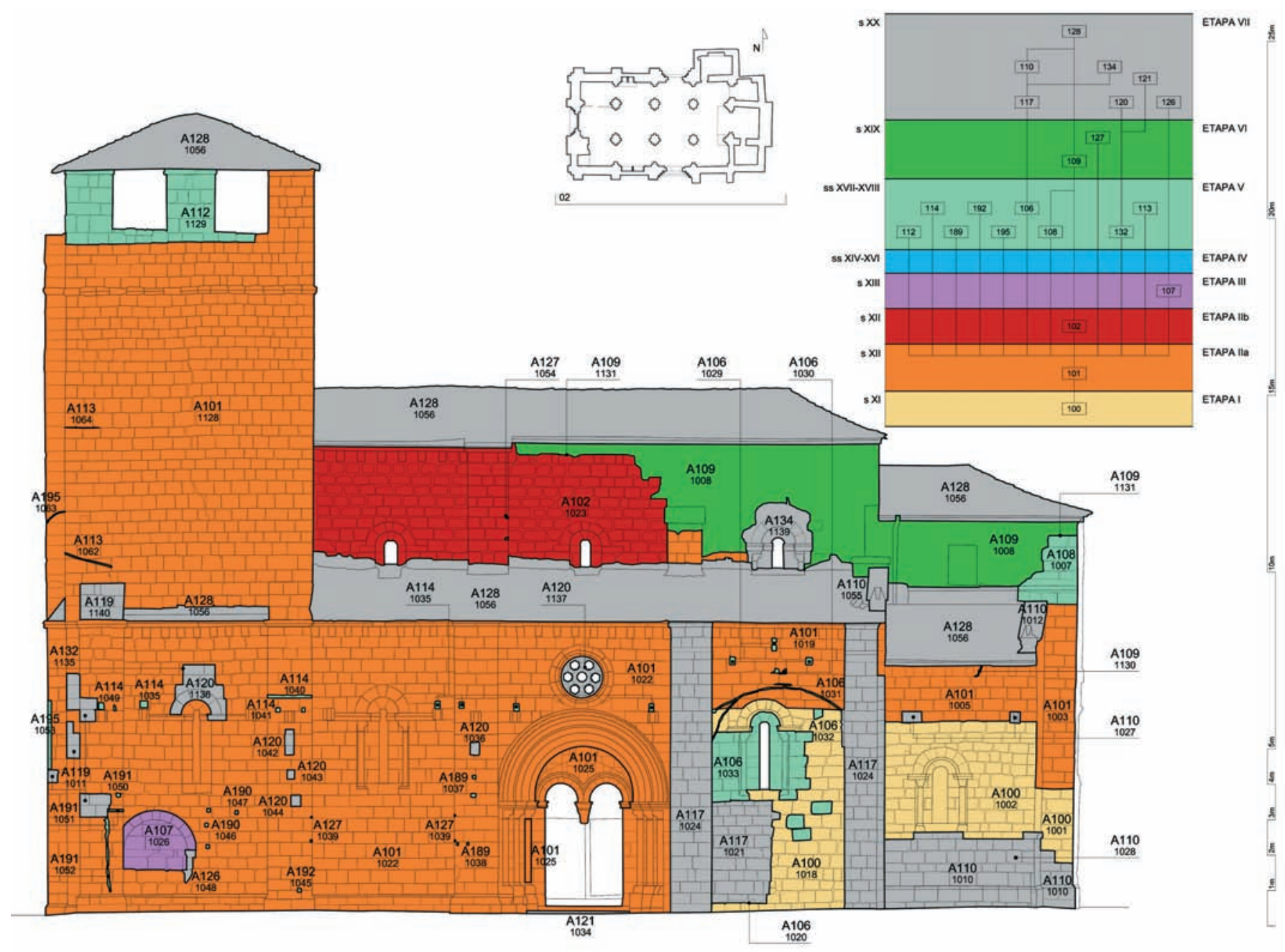

Fig. 13. Plano de UEs y As del alzado sur de Santiago del Burgo

mientos habituales de la puesta en carga, por lo que una grieta longitudinal recorre la clave y otras dos recorren los tercios inferiores, correspondiéndose así con las grietas descritas en el muro oeste (UE 1219, A 102), todas ellas rejuntadas con cemento.

Aunque la pareja de bóvedas orientales de la nave y la cabecera central se arruinaron, siendo restauradas a principios del siglo XIX en formas falsas de aristas (UE 1008, A 109), se puede intuir cómo fueron las formas primitivas. En la cabecera central, la prolongada altura de los muros y su luz $(4,42 \mathrm{~m})$ debieron ser un reto para una posible bóveda de cañón, análoga a las occidentales de la nave central, cuyas líneas de empuje se proyectarían ligeramente por encima de los muros laterales, lo que pudo provocar su ruina. La línea de imposta y el arco de embocadura corresponderían al arranque y perfil de la supuesta bóveda. Este tipo de cubierta pudo también emplearse en el primer tramo oriental de la nave central, no así en el siguiente. Aquí, las cuatros ménsulas en diagonal sobre el canto del pilar tienen únicamente sentido como soporte de las aristas de una bóveda ${ }^{11}$. Este segundo tramo oriental se enfatizaría así a modo de transepto gracias a la localización de los vanos de acceso en el eje Norte-Sur y de una bóveda de aristas que elevaría ligeramente su altura respecto a las contiguas de cañón en eje E-O.

Como remate final de la obra románica, las bóvedas fueron protegidas por una cubierta de losas de granito (UE 1273, A 118) dispuestas de manera contrapeada y con mortero de cal sellando sus juntas. Esta cubierta fue documentada, gracias al seguimiento arqueológico (Murillo 2008), en el extremo occidental de la nave lateral sur y de la central (Fig. 14), siendo lógica su extensión original por todo el edificio. Las puertas de la torre situadas respectivamente a nivel de la cubierta de la nave sur en su fachada

11 Gómez-Villaboa $(1912,21)$ también se fija en ellas, a partir de las cuales sugiere la probable existencia de un cimborrio cuyo inadecuado contrarresto fuese el motivo de la ruina de la parte oriental de la iglesia. Mencionadas también por Gómez Moreno (1927, 151). 


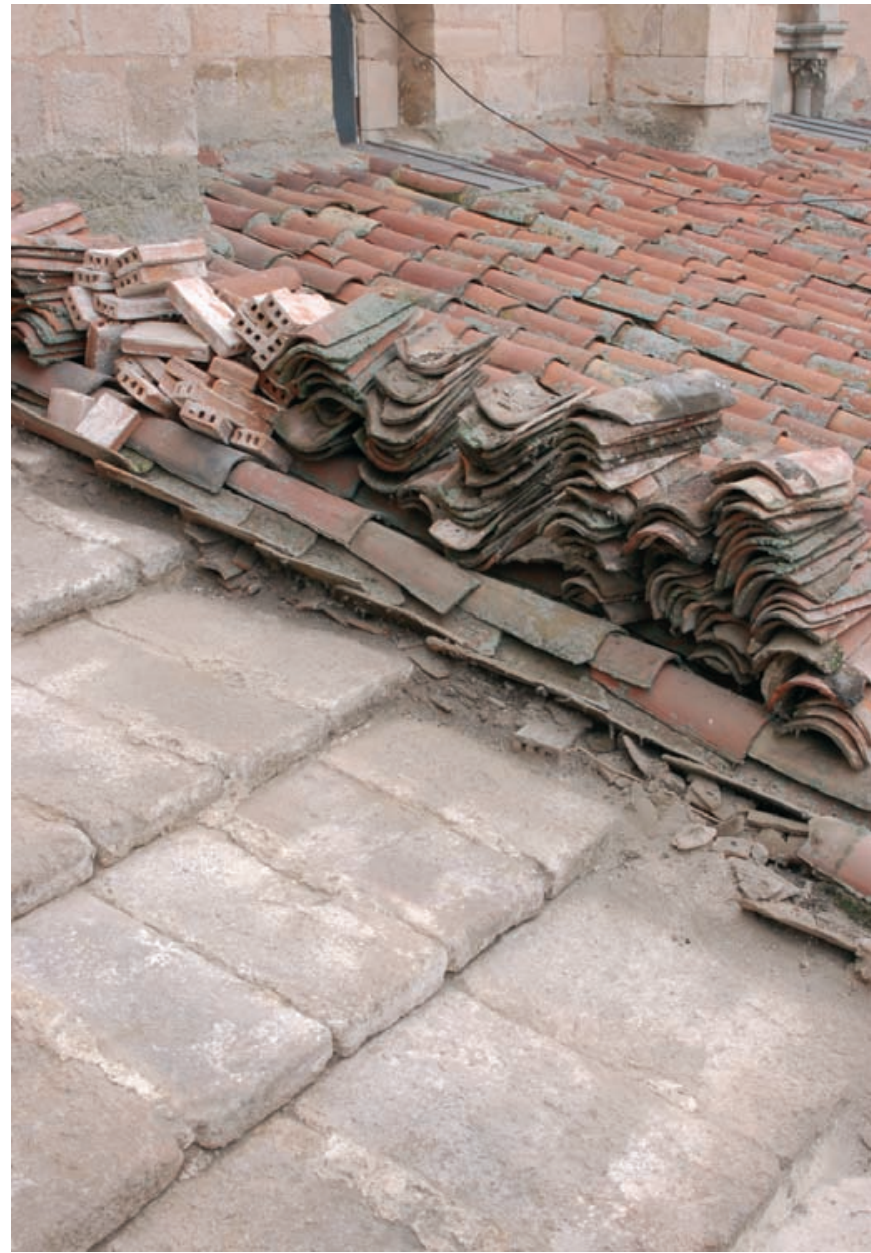

Fig. 14. Cubierta pétrea sobre el tercer tramo de la nave sur de la iglesia

este (Figs. 5 y 15) y a la altura de la cubierta superior en la fachada norte cobran ahora sentido, siendo los vanos que permiten el paso a la cubierta pétrea. A esto cabría sumar los pasos abiertos en los tímpanos sobre los dos arcos torales de las capillas laterales que nos indican un posible tránsito a este nivel (Figs. 5 y 15). Este hallazgo también permite comprender la mención en el Informe que presenta uno de los maestros licitantes, Andrés Frontera, a las obras de restauración del año 1820, en el que habla de «la escama de pez que cubre las bóvedas de dichas capillas».

\section{EL USO DE LA IGLESIA: TRANSFORMACIONES, ADICIONES Y RESTAURACIONES}

Concluida la construcción de la iglesia, su uso se refleja en una serie de obras que irán modificando paulatinamente su imagen. Las numerosas adiciones sufridas por el edificio apenas ofrecen relaciones directas entre ellas, por lo que los caracteres tipológicos, junto al sentido de la nueva configuración del espacio religioso, son los principales argumentos para ordenar temporalmente la secuencia. Con la inten- ción de evitar caer en una descripción parcial de la vida del edificio y teniendo presentes los límites de este trabajo, ofrecemos una síntesis de los capítulos más significativos de sus usos y transformaciones.

Etapa III (siglos XIII-XIV). Entre otros elementos, la iglesia se dota enseguida de capillas funerarias, que en forma de arcosolios horadan el extremo occidental del exterior de la fachada sur (UE 1026, A 107) y el tercer tramo desde el Este del interior de la nave norte (UE 1233, A 136; Fig. 7). El primero se reduce a un nicho de arco de medio punto, mientras que en el arcosolio interno se compone de un alfiz abocelado y una pareja de arcos de medio punto sobre tres grupos de tres columnillas. Su cota de apertura coincide con el nivel de uso de la Etapa II, pero sus elementos decorativos presentan un estilo atribuible ya a la Etapa III ${ }^{12}$.

Etapa IV (siglos XV-XVI). Las noticias reveladas por el material de archivo (Peláez y Casquero 2006, 11) indican que un convento de la Orden de Santo Domingo, cuyas primeras noticias se remontan al año 1465, fue anexionado a la iglesia a finales de la Edad Media. Asociamos a esta referencia las huellas de un forjado y su cubierta (UEs 111011141117 1120, A 156), documentadas en el extremo occidental de la fachada norte, y la necesaria apertura de una puerta en el muro norte del tramo más occidental (UE 1080, A 104) para facilitar la comunicación entre la iglesia y el convento. Los Libros de Visitas y Fábrica (año 1590) de la parroquia recogen que «en el cuerpo de la iglesia tienen las monjas una reja que sale a su coro", elemento que se puede relacionar con la existencia de dos vanos abiertos (UE 1271, A 138) en el muro del hastial occidental por encima de la portada (Fig. 17), a la altura del coro alto (UE 1220, A 140).

Como en la etapa anterior, continúa la construcción de capillas funerarias, las cuales son abiertas en relación a las nuevas cotas de circulación, algo más elevadas que en el momento inicial ${ }^{13}$, de tipología variadas, aunque con caracteres propios del estilo gótico tardío. En el muro del ter-

\footnotetext{
12 Abrantes $(1935,25)$ no observa que sean posteriores, pero comenta que sus características, como las del enfrentado en la nave sur (A 137) son propias de la segunda mitad del siglo XII. Del mismo modo, el arcosolio enfrentado de la nave sur (A 137) presenta características similares, aunque es de mayor tamaño y su arquería es ligeramente apuntada. Se introduce en la fábrica posteriormente, pero su cota de uso no corresponde a la de A 136, por lo que ha sido adscrito a la Etapa IV.

${ }^{13}$ La función cementerial de las iglesias conlleva sucesivas elevaciones del nivel de uso para ganar espacio de enterramiento. Gracias a los sondeos efectuados en los primeros pilares de la nave, sabemos que al menos hubo un par de elevaciones del nivel de uso (la segunda o última A 130), para introducir nuevas tumbas.
} 


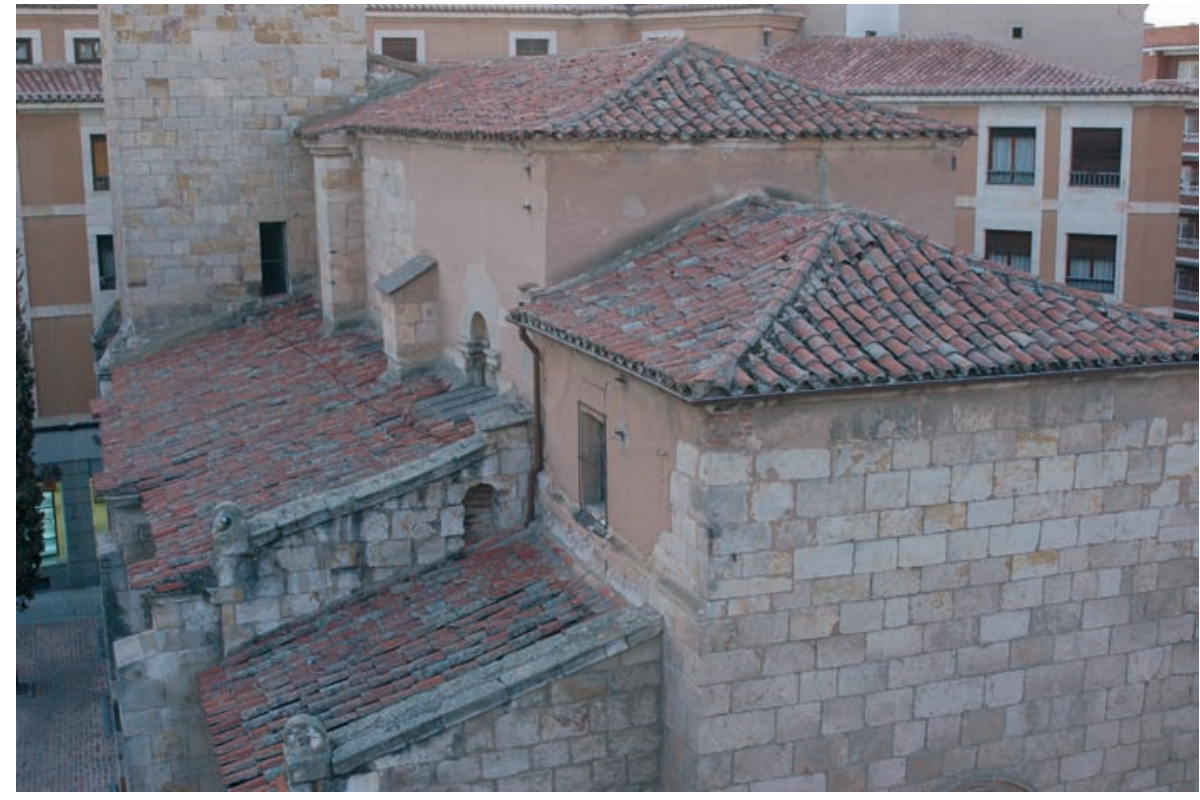

Fig. 15. Cuerpo superior del ábside y dos tramos orientales de la nave central de la iglesia cer tramo desde el Este de la nave sur, junto al pilar suroeste, se abre un nicho (UE 1251, A 137) de doble arquería apuntada sobre tres grupos de tres columnillas enmarcado por un alfiz con bocel, similar al arcosolio norte (UE 1233, A 136) enfrentado, pero de mayor tamaño. En el muro septentrional de la capilla norte, se abre un nuevo nicho del que conservamos tan solo las dos jambas laterales (UE 1184, A 150) con la clásica decoración de bolas tan prodigada en tiempos de los Reyes Católicos ${ }^{14}$ (Fig. 7). Al exterior del primer tramo oriental de la nave norte se adosa una capilla funeraria de planta cuadrangular (UE 1006, A 103), cubierta con una bóveda de crucería tripartita, la cual alberga un nicho rematado por un arco de medio punto. Construida en hiladas sinuosas, con leves saltos, con material de procedencia y dimensiones heterogéneas, la capilla se comunica con la iglesia mediante un nuevo vano (UE 1227, A 103) y se ilumina por un pequeño ventanuco abocinado en el muro este (Fig. 4).

Ya en el siglo XVI, se produce la adecuación como capilla funeraria del tramo occidental de la nave norte (A 105) mediante el cierre del vano del muro norte (UE 1081, A 105) y la apertura de tres arcosolios de arcos carpanel en la fábrica (UE 1239, A 105; Fig. 10). La familia Villareal, cuyos enterramientos ocupan el lugar (Luis de Villarreal, año 1554, y su hija Antonia, año $1552)^{15}$, financia la obra. Una nueva bóveda de crucería

14 Según Peláez y Casquero $(2006,16)$ «pertenece al desconocido Diego Osorio Laso de Castilla y Martel y su fecha se sitúa a caballo entre el siglo XV y XVI».

15 Según trascripción de los epitafios de Fernández Duro (1882, 262). A inicios del siglo XX, ya funcionaba como baptisterio (Gómez-Villaboa 1912, 22).
(UE 1242, A 105) sustituye a la original, desmontada previamente (UE 1241, A 105), y una reja (UE 1213, A 105) de estilo renacentista, datada en el último tercio del siglo XVI (Gallego de Miguel 1988, 75-78), delimita el nuevo espacio funerario.

Etapa V (siglos XVII-XVIII). El tiempo avanza y el convento continúa creciendo, proceso que se reconoce a través de la lectura combinada del edificio y de las fuentes escritas. La altura del convento fue elevada mediante nuevos forjados en la fachada occidental (As 113157 y 158), septentrional (A 195) y meridional (As 114189190 y 191). Este crecimiento implicó la apertura de una hornacina o estante (A 116) en la fachada norte, el cegado de las ventanas, al menos, de los tramos occidentales, y la apertura de nuevos vanos sobre la ventana original de los mismos tramos en las naves sur (A 132) y norte (A 155). Otra serie de agujeros (As 115193 y 194) son reconocidos a lo largo de la fachada norte, cuya altura podría corresponder a un cuerpo superior.

A partir de este momento, la cabecera comienza a ser un foco de atención estratigráfico, donde reconocemos una serie de adecuaciones y reparaciones. El testero del ábside mayor es realzado con un nuevo muro de sillería (UE 1007, A 108), del cual ignoramos el perfil de su remate original ${ }^{16}$ (Fig. 5). Hoy es recto. Esta acción debe coincidir con la introducción de un nuevo retablo (UEs

16 Por analogía con la vecina iglesia de San Esteban, la propuesta tradicional ha reconstruido un tímpano exterior y una bóveda de cañón al interior. 
1141 1142, A 145) de grandes dimensiones ${ }^{17}$, acción común en las iglesias ornamentadas con retablos barrocos, y con la apertura de sendos arcos en los muros interabsidiales (UE 1145, A 146; Fig. 10), aunque también pudo deberse a la intención de solucionar problemas estructurales en la cabecera. A este respecto traemos a colación el asiento del año 1744 de los Libros de Cuentas que dice: «Mas doy en data ciento y treinta reales vellón los mismos que costó el reparo de la bóveda de la capilla mayor que amenazaba gran ruina», complementado con otros trescientos dos reales «que costó la teja, cal y jornales que se gastaron en componer todo el tejado de la iglesia, que estaba muy derrotado" (PeLÁez y CASQUero 2006, 21). Según los mismos libros, la capilla central tenía problemas y el realzado del testero (UE 1007, A 108) pudo ser una solución. Sin embargo, se han documentado colapsos puntuales en zonas inmediatas a la cabecera que también pueden relacionarse con la descripción del año 1744: el desplome hacia el Sur de la capilla meridional (UE 1165, A 167), el desplazamiento y deformación de su bóveda (UE 1196, A 167) y el agrietamiento del primer pilar oriental de la arquería norte (UE 1198, A 167). Se aprecian reparaciones en los paramentos exteriores e interiores de las capillas central y norte (UEs 1009 1181, A 111) e interior de esta última (UE 1181, A 111) como indica el mismo de los Libros de Cuentas: «Mas doy en data cuatrocientos reales vellón los mismos que pagué y costó el socalce que se hizo por fuera de la Capilla Mayor de esta iglesia porque amenazaba total ruina» (Peláez y CASQuero 2006, 21).

Los Libros de Cuentas mencionan la construcción de una nueva sacristía, adosada a la fachada sur de la iglesia, en el año 1794. La documentación recoge que la sacristía existente presentaba problemas de espacio, humedad y oscuridad por lo que «mandó construir el mismo señor visitador a expensas suyas una nueva sacristía en lo que antes servía de capilla y uso de la Cofradía de Nuestra Señora de los Reyes, por estar en sitio a propósito para ello, $y$ en efecto ha quedado una pieza muy capaz, clara y libre de humedades, y con una ventana bien rasgada adornada con cristales, reja de hierro y red de alambre» (PELÁEZ y CASQuero 2006, 21 y 22). La visita referida indica que esta construcción ocupaba el «sitio de cabildo», denominación que parece referirse al pórtico meridional de la iglesia (EID. 2006, 22). Aun se pueden reconocer al exterior de la iglesia la huella de la bóveda vaída (UE 1031, A 106) que cubría esta estancia (Fig. 13).

\footnotetext{
17 Según Peláez y Casquero (2006, 18), el retablo mayor es una obra rococó que puede fecharse hacia 1780. Representa al apóstol Santiago a caballo en la batalla de Clavijo y como peregrino.
}

Etapa VI (siglo XIX). La lectura de paramentos pone de manifiesto que, con posterioridad a la reparación de la base del testero y realzado de la cabecera central, se producen una serie de movimientos en el edificio que conducen al colapso de su fábrica y fuerzan a intervenir en el cuerpo superior de la nave y la capilla central (Figs. 4 y 11). La aparición de una serie de grietas en las capillas norte (UE 1014, A 109) y sur (UE 1130, A 109) y una rotura en el alzado sur del tercer tramo de la nave central (UE 1224, A 109) debe relacionarse con estos movimientos. Pero la principal huella de este trastorno es la solución de continuidad (UE 1131, A 109) que delimita el desmonte controlado del área afectada para su inmediata reconstrucción. Comprende las zonas superiores de la cabecera central y los dos tramos orientales de la nave central, afectando en mayor medida a los dos cuerpos más orientales y sólo a la bóveda en el más occidental (Figs. 13 y 15).

Una vez instalados los medios necesarios para efectuar los trabajos, se llevó a cabo un desmonte controlado de las estructuras afectadas para levantarlas de nuevo, pero esta vez en materiales y formas diferentes. Se reconstruyen los muros de la cabecera central y del primer tramo oriental de la nave central en ladrillo y se iluminan con ventanas rectangulares, conservadas sólo en la cabecera ${ }^{18}$. Las dos bóvedas orientales de la nave central se efectúan con aristas marcadas y clave central ${ }^{19}$, mientras que la capilla principal se aboveda con una forma vaída con las aristas diagonales y la clave central marcadas.

La reparación del templo conlleva también la reconstrucción de los pilares y arcos de embocadura de las capillas laterales. En la embocadura norte, el pilar y arco internos son renovados por completo (UE 1177, A 170), momento que se aprovecha para poner un nuevo suelo (UE 1180, A 170). Se reconstruye el arco de embocadura de la capilla sur y la bóveda contigua del primer tramo de la nave (UE 1166, A 168).

Estas reparaciones suponen la reconstrucción de elementos muy alterados, pero también responden a tratamientos de contención para evitar la reproducción de estos problemas. De este modo, se cimbra la embocadura de la capilla sur con muros macizos de mampostería (UE 1167, A 169) y se tapian los arcos abiertos en los muro interabsidiales (UE 1146, A 169) con muros en los que se abren puertas adinteladas. Se rodea con un zuncho metálico el

\footnotetext{
${ }^{18}$ Las fotografías antiguas, previas a las reformas del templo en el año 1932, permiten comprobar que las cuatro ventanas se realizaron con la misma morfología rectangular.

${ }_{19}$ De panderete de ladrillo según Gómez-Villaboa (1912, 20), de yeso y ladrillo según Gómez Moreno (1927, 151).
} 


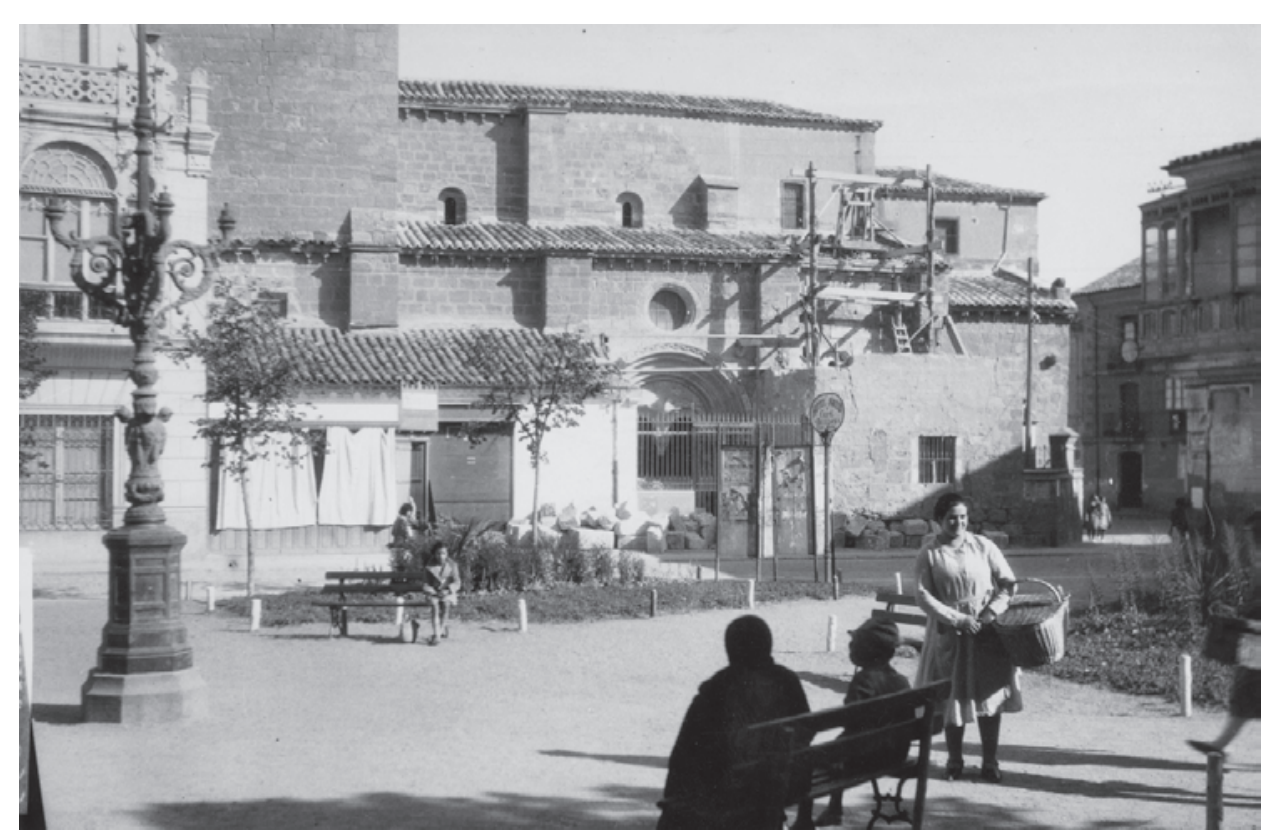

Fig. 16. Proceso de desmonte de la estancia adosada al sur de la iglesia (Diciembre 19311932, IPHE) pilar más oriental de la arquería sur (UE 1225, A 168), uno de los primeros elementos que colapsaron en esta etapa.

Por último, el convento de la Orden de Santo Domingo permaneció junto a la iglesia de Santiago del Burgo hasta que el gobernador eclesiástico las incorporó al Convento de San Pablo. Con el tiempo el convento fue derribado para posteriormente construirse una casa contigua (Casa de Isidro Rubio, industrial) sometida a una nueva alineación de la calle Santa Clara. En este momento, según PELÁEZ y CASQUERO (2006, 28), todavía se conservaba la casa del sacristán, el pórtico, la nueva sacristía y un transformador instalado por la compañía eléctrica El Porvenir de Zamora junto a la capilla meridional.

Etapa VII (siglo XX). La actuación más notable llevada a cabo en el edifico fue la restauración dirigida por el arquitecto Alejandro Ferrant Vázquez entre diciembre de 1931 y a lo largo del siguiente año de 1932, la cual tuvo como principal objetivo liberar a la iglesia de las construcciones adosadas que se habían ido apropiando de sus fachadas ${ }^{20}$, como la capilla adosada (A 106) en el lado sur (Fig. 16). También sustituyó las ventanas del primer tramo de la nave central por otras rematadas con un mortero cementoso (UE 1139, A 134), las cuales pretendían

\footnotetext{
${ }^{20}$ Gómez-Villaboa (1912, 22-23) menciona las casas adosadas a la fachada oeste, las cuales impiden el estudio de su portada, y comenta que «a excepción del triábside, [la iglesia] se halla verdaderamente encerrada y oprimida por edificaciones muy posteriores, dependencias unas y habitaciones particulares otras, que se han adherido a sus muros en el transcurso de los años».
}

simular el aspecto de las originales de la iglesia románica, y restituyó el rosetón de la fachada sur (UE 1137, A 120), cuyo original, había sido sustituido por una claraboya de cristal (Fig. 16). Ferrant cegó además los ventanucos abiertos en los tramos occidentales de las naves laterales (UEs 10601136 1238, A 120). La adecuación del acceso norte debió llevarse a cabo en este momento. La colección gráfica permite afirmar que entre los años 1932 y 1955 se eliminan de la fachada sur de la iglesia los edificios que se resistieron a la acción del arquitecto Ferrant, como el kiosco de frutas situado a los pies de la torre.

Una década después tienen lugar las reparaciones de la capilla meridional dirigidas por el arquitecto Luis Menéndez Pidal (1967), donde reconocemos reposiciones de cantería de aspecto moderno, como la que sustituye al recalce (UEs 1009 1181, A 111), abarcando toda la superficie exterior de la base de la cabecera (UEs 1010 1028, A 110; Fig. 5). Este material aparece también en partes más altas del muro y se une con la reposición de los elementos de la cornisa del frente oriental de la cabecera y, por similitud, de la nave sur (UEs 1012 1055, A 110). Menéndez Pidal señala que el movimiento de las partes agrietadas rompe los registros de yeso colocados para controlar la estabilidad de la zona afectada. Por esta razón, propone intervenir con un proyecto de obra de urgencia desmontando la esquina y bóveda de la pieza exterior de la capilla sur para rehacerla a continuación, consolidando y recalzando previamente los muros conmovidos por lo que el arquitecto interpretó como asientos del terreno (AGA, Fondo de Cultura, caja 120, en Peláez y Casquero 2006, 37 y 38). 


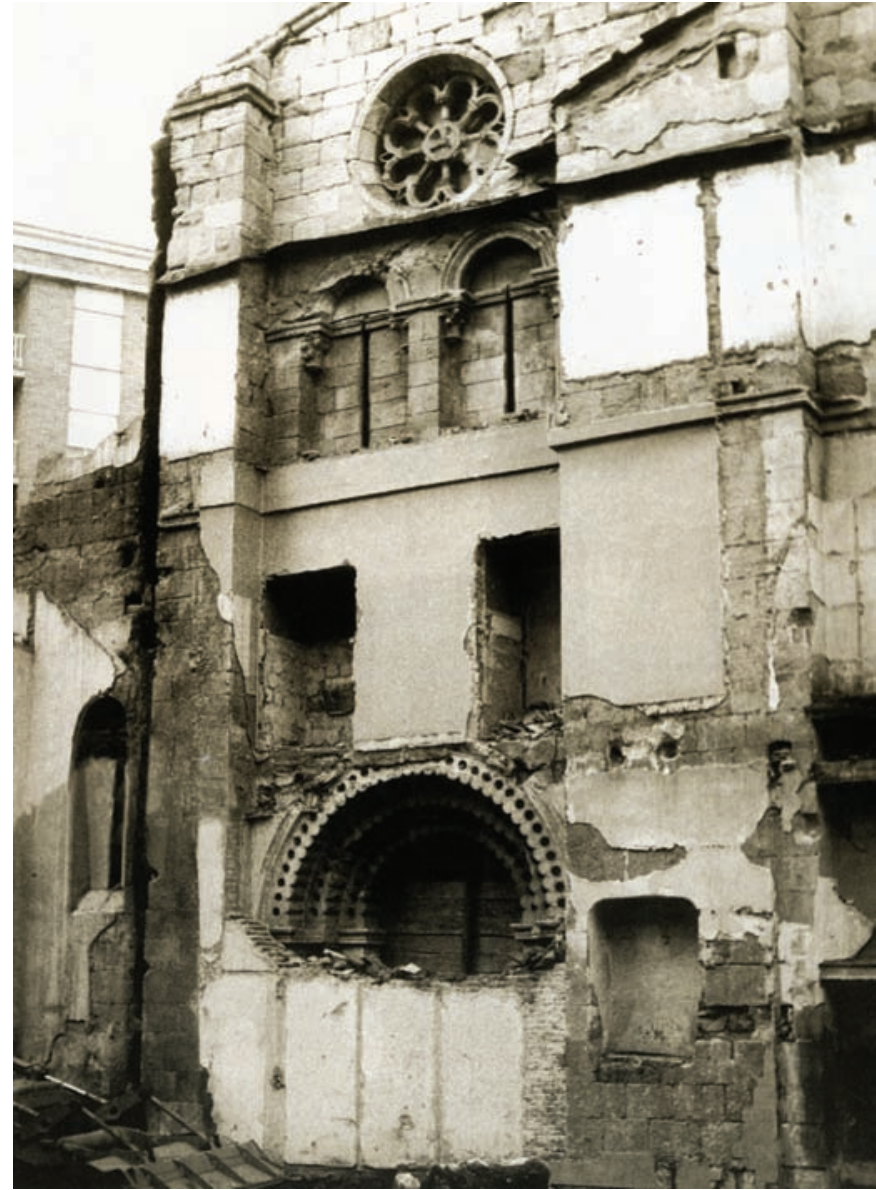

Fig. 17. Demolición de la casa adosada a la fachada oeste de la iglesia (1976, Colección Ángel L. Esteban Ramírez)

En el año 1976 se derribó la casa de Isidoro Rubio, adosada a los pies de la iglesia, con el objetivo de construir una nueva edificación a cierta distancia de la fachada del edificio. Esta acción dejó visibles todas las afecciones producidas por las diferentes estructuras adosadas a la fachada a lo largo de su historia, las cuales fueron reparadas en cantería (UEs 101111321140 1217, A 119; Fig. 17).

Por toda la iglesia identificamos varias reparaciones de carácter popular que tienen en común el empleo de materiales muy modernos, como el cemento, que se emplea para tapar grietas, agujeros (UEs 115111691197 1237 1240, A 174) o tapiar con ladrillo la puerta sobre la bóveda a los pies de la torre (UE 1263, A 121). En otros casos se emplea un mortero blanquecino (UE 1152, A 175). El cemento también es empleado en la instalación del sistema de calefacción, hecho lamentable que supuso la condena de la sacristía norte adosada al invadir su interior y alterar sus elementos ornamentales. La introducción de la chimenea afectó a la cubierta, se adosó la maquinaría al alzado sur interior de la estancia y se abrió un hueco cuadrado para arrojar el aire caliente al interior de la iglesia (UEs 12281232 1249, A 184).

\section{DEL PROTORROMÁNICO AL ROMÁNICO: DE LA ETAPA I A LA ETAPA II}

La obra de la Etapa I de Santiago del Burgo presenta un modelo de basílica de cabecera triple, la central ligeramente avanzada, y aula de tres naves, cuyo plan debió verse interrumpido, llegando a construirse los muros de sillarejo y sillería calizos de la zona oriental, pero no sus cubiertas. Este proyecto ya concibió el alzado de una capilla y una nave septentrionales más estrechas, pero necesariamente más altas, en una zona donde el nivel de suelo original desciende bruscamente hacia el Norte, como demuestran las distintas cotas de cimentación de los pilares (Figs. 6 y 18). También contempló la presencia de puertas laterales similares a las actuales.

La obra de la Etapa I quedó inacabada, pero determinó el desarrollo de la Etapa II, la cual continuó el proyecto iniciado de una basílica de tres naves y cabecera triple con una torre a sus pies. Su datación debe tener en cuenta la documentación escrita (año 1181) y el contexto arquitectónico románico, en el que los paralelos de los elementos decorativos siguen jugando un papel fundamental. Los ejemplos comparados con las portadas occidental ${ }^{21}$, septentrional ${ }^{22}$ y meridional ${ }^{23}$, calificadas como ejemplos típicos zamoranos tanto a nivel arquitectónico como decorativo, se mueven en estas mismas fechas, aunque la secuencia establecida fuerza a diferenciar ahora entre las piezas decorativas de la Etapa I y de la Etapa II ${ }^{24}$.

Las cubiertas pétreas documentadas dan sentido a los accesos originales del cuerpo de la torre y parecen ser un recurso común en otros edificios eclesiásticos de la zona, como el monasterio de la Granja de Moreruela, la Catedral de Zamora, la Colegiata de Toro o Santa María de

${ }^{21}$ Puerta del Obispo de la Catedral de Zamora y puerta sur de la iglesia arciprestal de San Pedro y San Ildefonso (Abrantes 1993-94, 22).

22 Las puertas de San Leonardo de Zamora y San Juan Bautista de Arroyo de Encomienda (Valladolid) presentarían el mismo almohadillado (Gómez Moreno 1927, 150 y Abrantes 1993-94, 24). Naval (1989) suma la portada norte de San Félix de Apiés (Huesca).

${ }^{23}$ En relación con las iglesias gallegas de San Pedro de Portomarín y la Catedral de Lugo, para las que se manejan fechas de finales del XII (Ávila de la Torre 2000, 114-115 y Peláez y Casquero 2006, 6-7).

${ }_{24}$ Al respecto, Gómez Moreno $(1927,152)$ identificó dos talleres decorativos correspondientes a dos impulsos constructivos. El primer taller se identificaría por un estilo corintio uniforme presente en las capillas, pilares y portadas. Otro taller, de rasgos más exuberantes y variados, realizaría los capiteles de los restantes pilares, arcos y bóvedas. Modelo seguido por Ramos $(1977,209-211)$ y Abrantes (1993-94, 26-27). Para Bango (1997, 311), la construcción de Santiago se prolongó tanto que gran parte de la obra sería ya tardorrománica. Herrero (2002) observa que los elementos antropomorfos presentan una tendencia naturalista que preludian el gótico. 


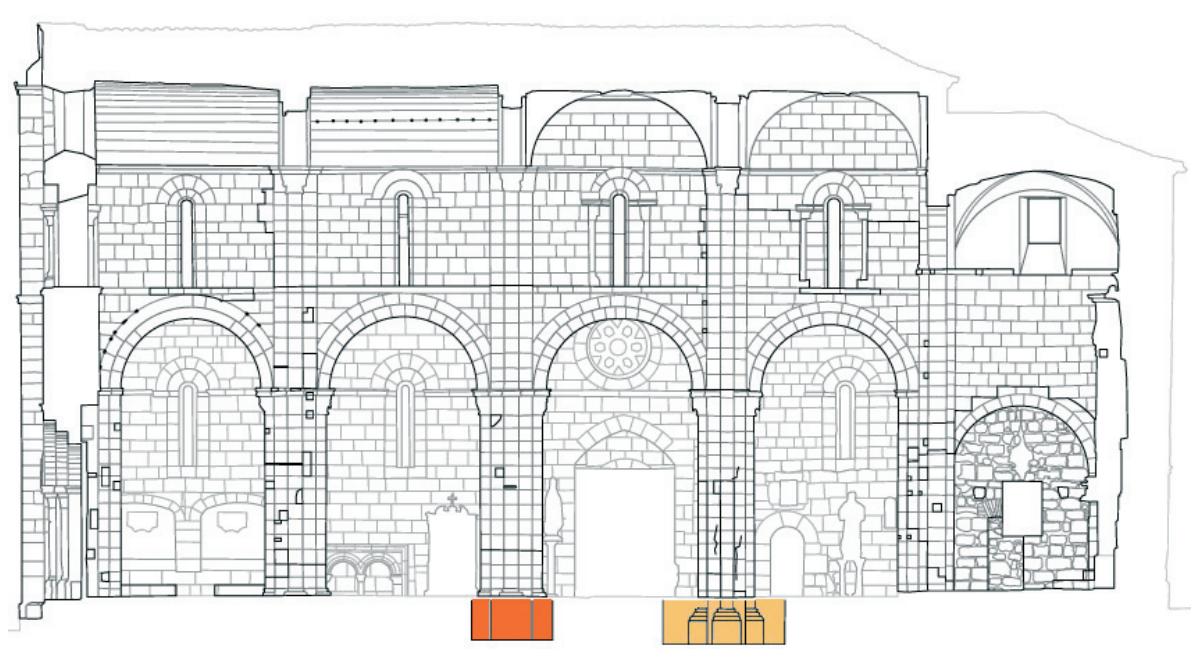

Fig. 18. Plano de la arquería norte de con las diferencias de cota entre las basas de los pilares de la arquería norte de la Etapa I (amarillo) y de la Etapa II (naranja)
Azogue $^{25}$. La realización de este tipo de cubiertas no hace más que incidir en la presencia de una mano de obra de cantería especializada.

No obstante, la basílica de la Etapa II ofrece novedades muy significativas para la historia de la arquitectura y de la construcción del primer románico, evidenciando no tanto un cambio tipológico como tecnológico. La introducción de la fábrica de sillería con abundantes marcas de cantero aparece como un elemento distintivo acotable en términos históricos, hecho que afecta tanto a la interpretación y cronología de la Etapa I como de la Etapa II (Fig. 19). La presencia de marcas de cantero de manera sistemática parece ser un fenómeno que comienza a constatarse en la Península (MORALEJO 1996) y en otras zonas europeas (BIANCHI 1997, AlEXANDER 2007 y ESQUIEU y HARTMANN-VIRNICH 2007), a priori, en la última década del siglo XI. Este dato, sumado a la primera cita histórica del lugar en $1181^{26}$, situaría a la Etapa II de Santiago del Burgo en la primera mitad del siglo XII y, de manera complementaria, a la Etapa I, para la cual no contamos con referencias escritas pero sí estratigráficas, a finales del

25 Referencias que agradecemos a H. Larrén. Sobre la cubierta de Santa María de Azogue, ver S/a 2008.

${ }^{26}$ Gómez Moreno $(1927,150)$ menciona una donación a la catedral de Zamora en el año 1168, la cual sería completada en 1176 . Ramos $(1977,203)$ considera que el documento de 1168 se refiere en realidad a la iglesia de Santiago el Viejo, pero da por válida la donación de 1176 e incorpora otra nueva, que completa a la anterior, de 1178 (seguidos por Abrantes 1993-94, 21). Como demuestra el vaciado documental (Pérez y Casquero 2006) consultado para la redacción del informe arqueológico (Murillo y Utrero 2008) y como también publica Rodríguez Montañés (2002, 437), la primera referencia documental segura sobre Santiago del Burgo es la fechada en el año 1181.

${ }^{27}$ La talla de la fábrica de esta Etapa I puede asimilarse a la identificada en algunas iglesias alavesas del Grupo 6 (Sánchez Zufiaurre 2008, 264, variable 44, y 281-288), aplicada principalmente en las jambas de los vanos y acotada cronológicamente desde el segundo tercio del siglo XI hasta avanzado el siglo XII. siglo $\mathrm{XI}^{27}$. Aunque los estudios sobre la evolución urbanística de la ciudad de Zamora reconocen tres recintos murarios alzados progresivamente a mediados del siglo XI, en el siglo XII y en el siglo XIV (LARRÉN 1999), estas murallas no deben condicionar la datación de Santiago del Burgo. De hecho, otras iglesias de Zamora, como Santo Tomé o San Leonardo, atribuidas a los siglos XII-XIII ${ }^{28}$, se sitúan dentro de la tercera muralla del siglo XIV, lo que indica que la expansión de la ciudad va incorporando zonas ya habitadas y dotadas de sus correspondientes edificios de culto. Es más, según REPRESA (1972, 528 y 531) y, más recientemente, GUTIÉRREZ (1993, 246-247), la repoblación de la ciudad dirigida por Raimundo de Borgoña a finales del siglo XI se expandió rápidamente del núcleo catedralicio hacia las pueblas de S. Torcuato, Sto. Tomás del Valle, Valborraz y el Burgo. Esta última, de acuerdo con el análisis efectuado, contemplaría rápidamente la construcción de la iglesia de Santiago.

Del mismo modo, el carácter arcaico de la cabecera triple plana con capilla central avanzada señalado por algunos investigadores se explica ahora dentro de una secuencia en la que precisamente esta zona del edificio se sitúa en un momento anterior a la gran iglesia románica que hoy vemos. No es un elemento arcaico de la basílica del siglo XII, sino un espacio anterior.

De esta forma, la escasa presencia de sencillas marcas de cantero, la tipología paramental (empleo de sillarejo con sillería puntual) y planimétrica (cabecera plana) junto con la secuencia relativa argumentarían una datación temprana

28 Santo Tomé, de finales del siglo XI para Gómez Moreno (1927, 88-90, documentos del 1093 y 1128), de inicios del XII para Ramos (1977, 222 documento 1128); o San Leonardo, con menos documentación, de finales del XII o inicios del XIII (Gómez Moreno 1927, 154 y Ramos 1977, 180). 

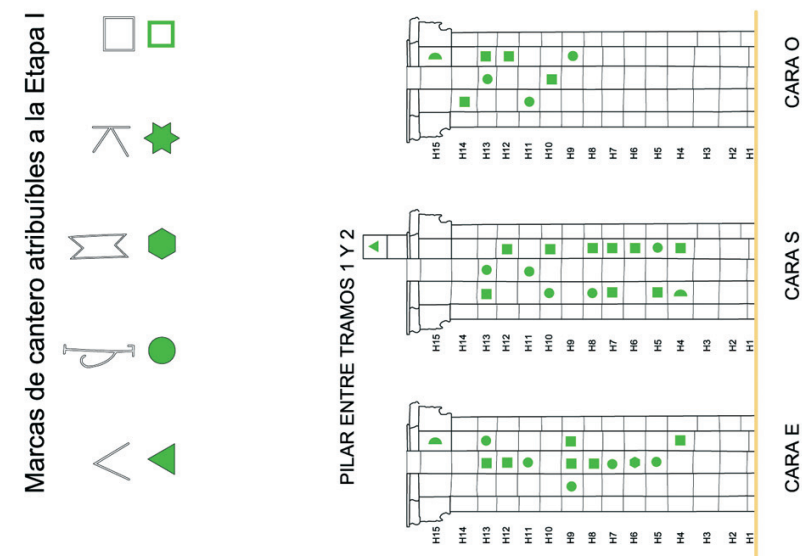

$\stackrel{-(6)}{\longrightarrow}$

艾
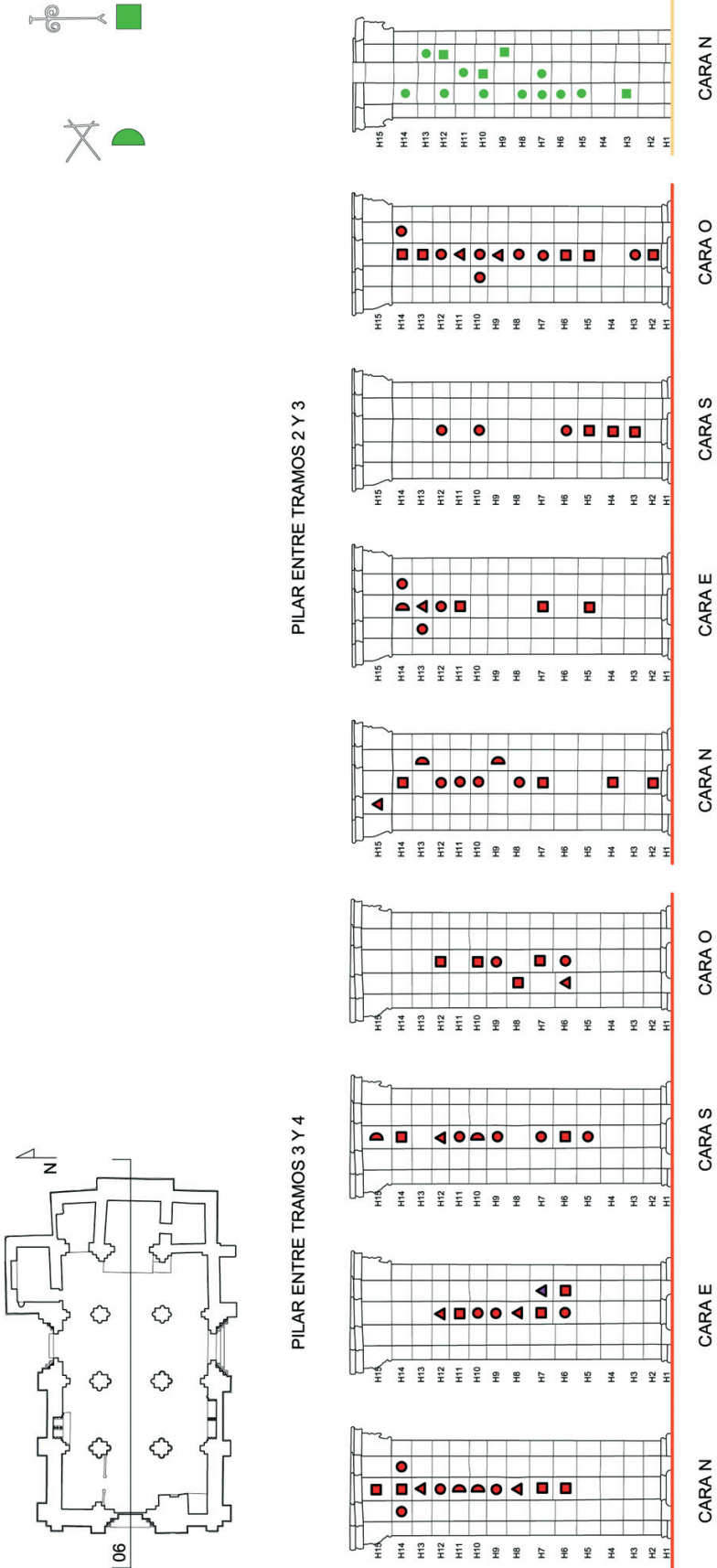

票

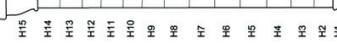

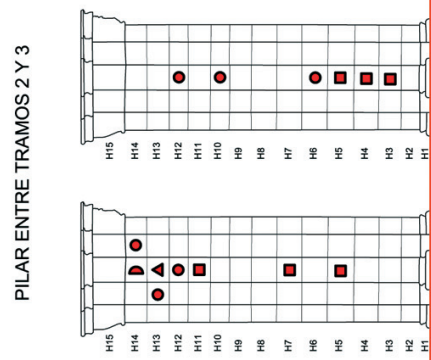

$\sqrt{3}$
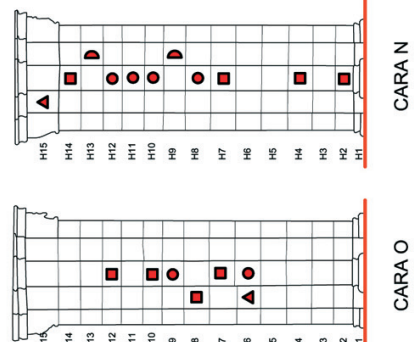

旁

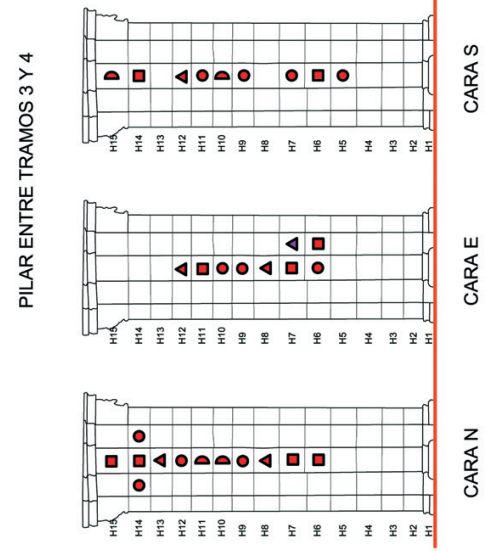

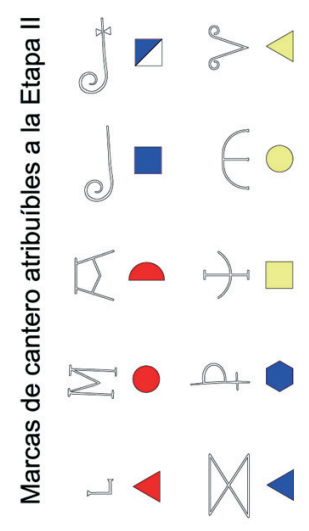

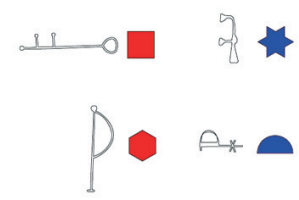

$\int+5$
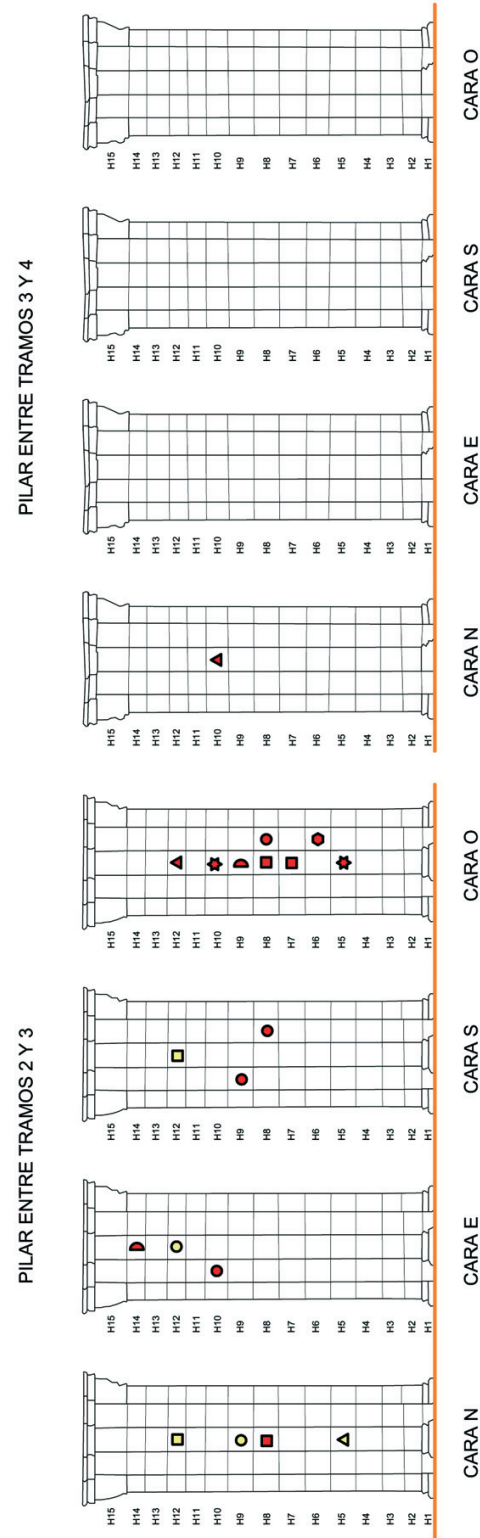

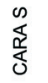

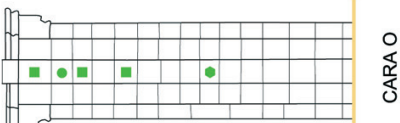

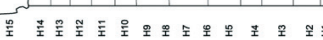
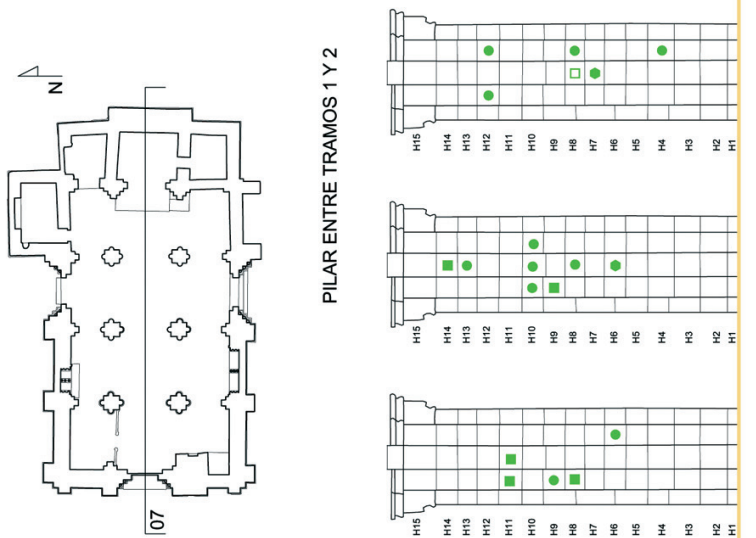

峁

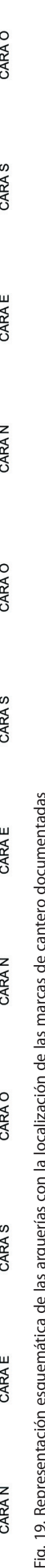


de finales del siglo XI para una iglesia hasta ahora desconocida (Etapa I), de la cual se llegó a construir la cabecera y el primer tramo oriental del aula. La estratigrafía confirma así las sospechas de GARNACHO $(1878,151-153)$ sobre la aparente existencia de dos fábricas de dos épocas distintas con origen a finales del siglo XI o de CeDILLO $(1915,358)$ al calificarla, precisamente por el tipo de cabecera, como una derivación de las iglesias asturianas de los siglos VIII al XI. Se descubre una obra inédita y clave para analizar el paso del Protorrománico al Románico en la ciudad de Zamora y, por extensión, del centro de la Meseta. Su conexión con otros estudios arqueológicos efectuados recientemente ${ }^{29}$ puede ser enriquecedora y sugerente para el conocimiento de este sector del urbanismo zamorano durante este periodo.

Esta primera basílica (Etapa I) parece que sufrió un cambio de constructor, abandonándose la forma de hacer anterior y asistiendo a la implantación de un nuevo proyecto (Etapa II) que, aunque continúa el modelo basilical original, forma parte de un contexto productivo y, probablemente, social totalmente distinto, del cual, el notable incremento del número y complejidad de las marcas de cantero son su máximo exponente. A partir de ahora, la obra avanza de Este a Oeste y de abajo a arriba de manera simultánea. La identificación de juntas de obra, fruto de la convergencia de distintos esfuerzos y/o cuadrillas constructivas que actúan al tiempo, es la base para descifrar esta evolución. En un primer momento (Etapa IIa) se construye el perímetro del aula con sus naves laterales cubiertas con bóvedas de aristas e iluminadas con ventanas y rosetones, las arquerías de división, las tres portadas de acceso y la torre occidental. En un segundo momento (Etapa IIb), se alzan los tramos centrales de la nave central y se aboveda con formas de medio cañón y de aristas. Aunque la ruina del sector oriental nos impide confirmarlo, parece lógico pensar que la bóveda de la cabecera central se realizase en este mismo momento. Las soluciones de continuidad, el cambio de técnica paramental (sillería) y tipológico de sus elementos singulares así como la notable presencia de marcas de cantero son los principales indicios para distinguir este nuevo proyecto (Etapa II) frente al anterior (Etapa I). Las referencias documentales (año 1181) y los estilos de los elementos decorativos, los cuales deben ser revisados a la luz de los resultados de esta lectura por los historiadores del Arte, parecen refrendar una fecha avanzada del siglo XII

29 Sintetizados por Larrén (1999). En torno a los trabajos realizados en el exterior de la cabecera de la iglesia con motivo de la urbanización de la plaza, durante los cuales se documentaron restos de un cementerio, no conocemos datos. para la finalización de la basílica románica. Como en la Etapa I, la información material revelada por la basílica románica debe integrarse en la historia de la Arquitectura y de la construcción de este periodo, al ponerse de manifiesto un cambio tecnológico y una forma de construir programada con la participación de canteros que dejaron su rúbrica en la piedra.

\section{MÁS ALLÁ DEL EDIFICIO. LAS MARCAS DE CANTERO}

La lectura de paramentos permite acercarnos a la realidad material de un edificio con una rica secuencia histórica reflejada en sus muros, testigos del paso del tiempo y de las acciones que afectaron su integridad.

Junto a la novedad que supone el reconocimiento de dos proyectos constructivos sucesivos en la iglesia de Santiago del Burgo, subrayado en el epígrafe anterior, nos atrevemos ahora a realizar un ejercicio de distanciamiento de la realidad material del edificio, con el objetivo de ofrecer una reflexión, en nuestra opinión, relevante en lo que se refiere al papel de las marcas de cantero como indicador cronológico y socio-productivo en la historia de la construcción.

Las marcas de cantero deben tomarse en cuenta dentro del modelo de análisis estratigráfico como una variable más en la definición del tipo paramental. Aunque su estudio cuenta con un largo recorrido, las marcas de cantero apenas han sido sometidas a la estratigrafía muraria $^{30}$. La lectura conjunta de muros y marcas conduce a varias puntualizaciones. El hecho de que las mismas marcas aparezcan en otros edificios que, aunque con cronologías similares, no tienen porqué ser coetáneos, desestima la idea de la presencia de un mismo cantero. Es más, se debe entender que su uso dependía posiblemente del «jefe de obra» (ALEXANDER 2007, 65), quien controlaba mediante este sistema de marcas o, en realidad, signos de autoría ${ }^{31}$, el volumen de piedra tallada por cada cantero. $\mathrm{Y}$ a la inversa. Si el primer proyecto (Etapa I) no requiere este sistema de control, se debe desprender que el grupo de canteros es menor, tal vez superado por el número de albañiles, verdaderos protagonistas de la obras, encargados de convertir los sillarejos irregulares en una estructura muraria coherente.

\footnotetext{
${ }^{30}$ Las marcas fueron consideradas como una variable más de los grupos constructivos diferenciados en la catedral vieja de Santa María de Vitoria-Gasteiz (Fernández de Jauregui y Solaun 2001). Igualmente contempladas en el análisis estratigráfico de la iglesia de San Isidoro de León (Murillo y Utrero 2009).

${ }^{31}$ No reconocemos en Santiago del Burgo marcas que puedan corresponder al tipo de signos de procedencia de canteras, de colocación o de diseño (según tipos de Alexander 1996 y Reveyron 2003).
} 

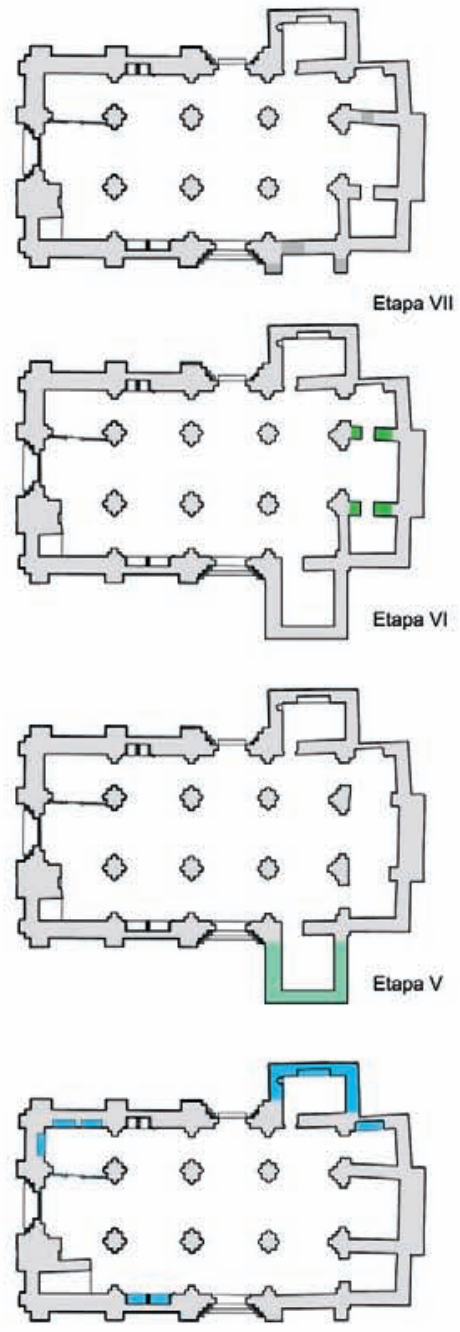

Etapa IV

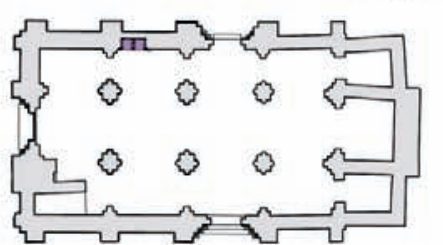

Etapa III

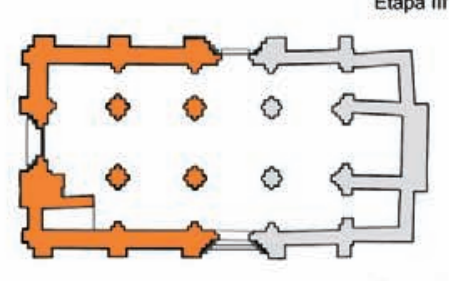

Etapa II

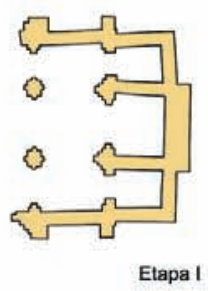

Fig. 20. Síntesis de la evolución en planta de Santiago del Burgo
Santiago del Burgo establece así una doble relación «mampostería - albañil - protorrománico», por un lado, y «sillería - cantero - románico», por otro. A su vez, el alto número de iglesias románicas del casco urbano de Zamora refleja un incremento de la actividad constructiva, fruto de un contexto económico que puede permitírselo. El hecho de que la sillería con marcas de cantero (Etapa II) reemplace al sillarejo (Etapa I) refleja el mismo fenómeno: canteros que esperan ser pagados por el número de sillares cortados, cuya elaborada talla permitiría ajustar las juntas, disponer hiladas regulares y horizontales, crear sillares "prefabricados ${ }^{32}$ (como los de los pilares cruciformes) y, en definitiva, dinamizar la construcción del edificio. Pero la sustitución del sillarejo por la sillería también nos conduce a las canteras, las cuales, considerando el número de construcciones en marcha en la Zamora de ese momento, debían ser numerosas y suficientemente organizadas para garantizar el abastecimiento a las obras de la ciudad. Todos estos elementos en conjunto (sillería, marcas, estandarización) evidencian un proceso de profesionalización y organización de la construcción (STALLEY 1999, 106-107) que irá consolidándose a lo largo del siglo XII.

Por lo tanto, podemos decir, como cierre de esta cadena que comienza en el edificio y que, por ahora, dejamos en la cantera, que Santiago del Burgo no es más que un pequeño reflejo de lo que un análisis estratigráfico puede aportar el estudio de un periodo como el Románico, cuya génesis no reside tanto en reconocer las influencias exteriores $^{33}$, sino como en identificar el funcionamiento de su contexto productivo inmediato.

Esta iglesia matriz románica es respetada a lo largo de su historia (Fig. 20). La adición de espacios conventuales y funerarios no supone la mutilación de los primitivos, los cuales no son sin embargo respetados por las ruinas de origen estructural. Estas arrastraron consigo gran parte de la nave y cabecera central y fueron el principal reto a resolver por los arquitectos restauradores del siglo XX, quienes, a diferente escala, son culpables y responsables del aspecto actual del edificio. Su entrada, primero, en el circuito de las restauraciones promovidas por la Segunda República de la mano de Alejandro Ferrant Vázquez, Arquitecto Conservador de Monumentos (1929-36) y, después, por Luis Menéndez Pidal, nuevo Arquitecto Conservador de Monumentos de la Primera Zona (1941-75), evidencia el objetivo del momento de recuperar la imagen histórica del edifi-

32 En términos de Kimpel (1977).

33 Aquellas de origen oriental y francesa (Gómez Moreno 1927, en adelante) han justificado el tipo arquitectónico y decorativo de las tres portadas de Santiago. 
cio que, como en el caso conocido de las murallas urbanas, se resume en la eliminación de todas las estructuras adosadas a lo largo del tiempo, perdiéndose una importante parte del uso e historia de la iglesia. Santiago del Burgo parece así desafiar al tiempo, aunque no a los proyectos de restauración, siempre la penúltima fase de su historia.

\section{BIBLIOGRAFÍA}

Abrantes Bernardo, R. 1993-1994, La iglesia románica de Santiago del Burgo en Zamora, Anales de Historia del Arte 4, 19-29.

Alexander, J. S. 1996, Masons' Marks and Stone Bonding, Tatton-Brown, T. and Munby, J. (ed.), The Archaeology of Cathedrals, Oxford University, 219236.

- 2007, The Introduction and Use of Masons' Marks in Romanesque Buildings in England, Medieval Archaeology 51, 63-81.

Ávila DE LA ToRre, Á. 1997, Estudio de las intervenciones y proyectos de restauración de las iglesias románicas de la ciudad de Zamora en los siglos XIX y XX, Inédito, Instituto de Estudios Zamoranos «Florián de Ocampo».

- 2000, Escultura románica en la ciudad de Zamora, Zamora.

Bango Torviso, I. G. 1997, El arte románico en Castilla y León, Madrid.

BiANCHI, G. 1997, I segni dei tagliatori di pietre negli edifici medievali. Spunti metodologia ed interpretativi, Archeologia dell'Architettura II, 25-37.

Calvo Madroño, I. 1914, Descripción geográfica, histórica y estadística de la provincia de Zamora, Madrid.

Cenillo, Conde de 1915, La iglesia de Santiago del Burgo, en Zamora, Boletín de la Real Academia de la Historia LXVI, 354-359.

DOMínguez HerRero, C. 2002, El románico zamorano en el marco del noroeste. Iconografia y simbolismo, Zamora.

Esquieu, Y. y Hartmann-Virnich, A. 2007, Les signes lapidaires dans la construction médiévale: études de cas et problèmes de méthode, Bulletin Monumental 165/4, 331-358.

FernándeZ de Jauregui, A. y Solaun, J. L. 2001, Indicadores cronotipológicos: análisis de tallas y signos lapidarios aplicados al estudio de la catedral de Santa María de Vitoria-Gasteiz, V Congreso de Arqueología Medieval Española, Valladolid, vol. 1, 273-280.

Gallego De Miguel, A. 1988, Rejería castellana: Zamora, Valladolid.

Garnacho, T. M. 1878, Breve noticia de algunas antigüedades de la ciudad y provincia de Zamora, Zamora.

Gómez Moreno, M. 1927 (1980), Catálogo monumental de España. Provincia de Zamora, 2 Tomos, Madrid.

Gómez-VillaboA, M. 1912, La Iglesia de Santiago del Burgo, Boletín del Centro Excursionista de Zamora III/11, Octubre, 17-27.

Gudiol, J. y GaYA, J. A. 1948, Arquitectura y Escultura Románicas, Ars Hispaniae $V$, Madrid.

Gutiérrez GonZÁlez, J. A. 1993, La ciudad de Zamora entre el mundo antiguo y el feudalismo: morfología urbana, IV Congreso de Arqueología Medieval Española, Alicante, t. II, 243-250.

Kimpel, D. 1977, Le développement de la taille en série dans l'architecture médiévale et son rôle dans l'histoire économique (1), Bulletin Monumental $135,196-222$.

LARRÉN IZQUIERDO, H. 1999, La evolución urbana de la ciudad de Zamora a través de los vestigios arqueológicos, VALDÉs, F. (coord.), III Congreso sobre la Península Ibérica y el Mediterráneo entre los siglos XI-XIII: El Urbanismo de los Estados Cristianos Peninsulares, Palencia (Aguilar de Campoo 1998), 91-118.

Moralejo, S. 1996, Saint-Jacques-de-Compostelle. Les origines d'un chantier roman, AA.VV., Chantiers médiévaux, Paris, 127-143.

Murillo, J. I. 2008, Arqueología de la Arquitectura: Iglesia de Santiago del Burgo, Zamora. Control arqueológico pavimento interior y cubiertas, Madrid (manuscrito depositado en la Consejería de Cultura y Turismo de la Junta de Castilla y León).

- Utrero, M. á Á. 2008, La iglesia de Santiago del Burgo, Zamora. Lectura de paramentos, 2008, Madrid (manuscrito depositado en la Consejería de Cultura y Turismo de la Junta de Castilla y León).

- EID. 2009, Arqueología de la Arquitectura. Basílica de la Real Colegiata de San Isidoro de León, 2008, Madrid (manuscrito depositado en la Consejería de Cultura y Turismo de la Junta de Castilla y León).

Naval Mas, A. 1989, Dos singulares portadas de idéntica realización: San Félix de Apies (Huesca) y Santiago del Burgo (Zamora), VI Congreso Español de Historia del Arte, Santiago de Compostela (1986), t. II, 307-317.

Peláez Franco, P. y Casquero Fernández, J. A. 2006, La Iglesia de Santiago del Burgo. Historia y fuentes documentales para su estudio, Inédito, Servicio Territorial de Cultura de Zamora, Junta de Castilla y León.

Ramos De Castro, G. 1977, El arte románico en la provincia de Zamora, Zamora.

Represa, A. 1972, Génesis y evolución urbana de la Zamora medieval, Hispania $32,525-545$.

Reverron, N. 2003, Marques lapidaires: The State of the Question, Gesta XLII/ 2, 161-171.

Rivera de las Heras, J. Á. 2001, Por la catedral, iglesias y ermitas de la ciudad de Zamora, León.

Rodríguez Montañés, J. M. 2002, La iglesia de Santiago del Burgo, García GuineA, M. Á. y Pérez GonzÁlez, J. M.a (Coord.), Enciclopedia del Románico en Castilla y León, Zamora, Aguilar de Campoo, 437-448.

SÁnchez Zufiaurre, L. 2008, Técnicas constructivas medievales. Nuevos documentos arqueológicos para el estudio de la Alta Edad Media en Álava, Vitoria.

Stalley, R. 1999, Early Medieval Architecture, Oxford.

S/a, 2008, Coronada en piedra. La cubierta de la iglesia de Santa María de Azogue recupera su original techumbre pétrea, Patrimonio. Revista de la Fundación del Patrimonio Histórico de Castilla y León 33, 20-27.

Recibido: 2 de octubre de 2008 Aceptado: 13 de enero de 2009 


\section{APÉNDICE}

\section{Santiago del Burgo (Zamora). Listado de actividades}

E. $=$ Etapas. Act. = Actividades.

El texto no trata la secuencia del edificio al completo y pormenorizadamente y, además, no incluye toda la planimetría necesaria para su seguimiento gráfico. Por esta razón hemos optado por ofrecer un listado de actividades, sin incluir las unidades estratigráficas que aglutinan.

\begin{tabular}{|c|c|c|c|c|}
\hline $\mathrm{E}$ & Act & Descripción & Anterior a & Posterior a \\
\hline I & 100 & $\begin{array}{l}\text { Ábsides y primer tramo de las naves laterales con sillería sin escuadrar. } \\
1^{\text {a }} \text { etapa de obra }\end{array}$ & $\begin{array}{l}101103106111117119131133 \\
148 / 150152153167 / 170173 / 175 \\
177 / 181184 / 186\end{array}$ & \\
\hline IIa & 101 & $\begin{array}{l}\text { Naves laterales y alzado de los pies con tramos orientales de la nave central y } \\
\text { torre. } 2^{\text {a }} \text { etapa de obra }\end{array}$ & 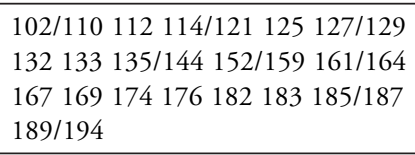 & 100 \\
\hline IIb & $\begin{array}{l}102 \\
118 \\
147\end{array}$ & $\begin{array}{l}\text { Tramo occidental de la nave central. } 3^{\text {a }} \text { etapa de obra } \\
\text { Cubierta de losas de piedra } \\
\text { Puesta en carga de las bóvedas }\end{array}$ & $\begin{array}{l}109118124127128147176183 \\
124128187\end{array}$ & \begin{tabular}{|l|l|}
101 \\
101 & 102 \\
102
\end{tabular} \\
\hline III & $\begin{array}{l}107 \\
124 \\
135 \\
136\end{array}$ & $\begin{array}{l}\text { Arcosolio extremo occidental fachada sur } \\
\text { Reparación de la cubierta } \\
\text { Reja de hierro de la ventana del ábside central } \\
\text { Arcosolio interior tercer tramo nave norte }\end{array}$ & $\begin{array}{l}126 \\
128 \\
166\end{array}$ & $\begin{array}{ll}101 \\
102 & 118 \\
101 \\
101\end{array}$ \\
\hline IV & $\begin{array}{l}103 \\
104 \\
105 \\
131 \\
137 \\
138 \\
139 \\
140 \\
148 \\
149 \\
150 \\
156\end{array}$ & $\begin{array}{l}\text { Capilla norte } \\
\text { Puerta en el cuarto tramo del alzado norte exterior } \\
\text { Adecuación como capilla del tramo occidental de la nave norte } \\
\text { Reja de la ventana septentrional del ábside norte } \\
\text { Arcosolio interior tercer tramo nave sur } \\
\text { Apertura de dos vanos en la fachada oeste } \\
\text { Posible coro bajo } \\
\text { Posible coro alto } \\
\text { Ampliación de las ventanas de los ábside laterales } \\
\text { Picado de las molduras interiores de los ábsides laterales } \\
\text { Arcosolio interior en el ábside norte } \\
\text { Huellas de un forjado y cubierta en el alzado norte exterior }\end{array}$ & $\begin{array}{l}123128184188 \\
105 \\
120125174 \\
163 \\
160 \\
\\
\\
111150 \\
151170\end{array}$ & $\begin{array}{l}100101 \\
101 \\
101 \\
100 \\
101 \\
101 \\
101 \\
101 \\
100 \\
100 \\
100149 \\
101\end{array}$ \\
\hline $\mathrm{V}$ & $\begin{array}{l}106 \\
108 \\
111 \\
112 \\
113 \\
114 \\
115 \\
116 \\
123 \\
130 \\
132 \\
145 \\
146 \\
151 \\
152 \\
153 \\
154 \\
155 \\
157 \\
158 \\
159 \\
160 \\
161 \\
162 \\
163 \\
167\end{array}$ & $\begin{array}{l}\text { Capilla sur } \\
\text { Recrecido del frente oriental del ábside central } \\
\text { Reparación de la zona inferior de la fachada exterior de los ábsides central y norte } \\
\text { Reparación de la torre } \\
\text { Huellas de cubierta sobre la fachada oeste exterior } \\
\text { Huellas de cubierta sobre el cuarto tramo de la fachada sur exterior } \\
\text { Agujeros en el ábside norte exterior } \\
\text { Hornacina } \\
\text { Pavimento exterior } \\
\text { Necrópolis bajo tarima (genérico) } \\
\text { Apertura ventana cuadrangular } \\
\text { Retablo del ábside central } \\
\text { Apertura de arcos entre ábsides } \\
\text { Reparación del arcosolio interior en el ábside norte } \\
\text { Picado y pintura figurativa en la embocadura del ábside central } \\
\text { Enlucidos } \\
\text { Picado en el tercer tramo de la nave norte } \\
\text { Ventana en el cuarto tramo de la nave norte } \\
\text { Huellas de un nuevo forjado y cubierta en el alzado norte exterior } \\
\text { Posible extensión de los elementos de la A157 } \\
\text { Pavimento de lajas de pizarra } \\
\text { Cegado de dos vanos } \\
\text { Uso del espacio sobre bóveda a los pies de la torre } \\
\text { Desmonte de la bóveda a los pies de la torre } \\
\text { Tranca de la portada meridional } \\
\text { Movimientos estructurales en el ábside sur }\end{array}$ & $\begin{array}{l}117177184 \\
109 \\
110118123170 \\
128 \\
195 \\
129 \\
125166 \\
120 \\
171 \\
153169 \\
174 \\
145172 \\
120128 \\
166 \\
119 \\
164 \\
168169174181\end{array}$ & $\begin{array}{ll}100101 \\
101 \\
100149 \\
101 \\
101 \\
101 \\
100101 \\
101 \\
100103111 \\
\\
101 \\
146153 \\
100101 \\
150 \\
100101 \\
100101146 \\
101 \\
101 \\
101 \\
101 \\
101 \\
138 \\
101 \\
101 \\
101 \\
100\end{array}$ \\
\hline
\end{tabular}




\begin{tabular}{|c|c|c|c|c|}
\hline $\mathrm{E}$ & Act & Descripción & Anterior a & Posterior a \\
\hline & $\begin{array}{l}173 \\
179 \\
188 \\
189 \\
190 \\
191 \\
192 \\
193 \\
194 \\
195\end{array}$ & $\begin{array}{l}\text { Agujeros tras el retablo del ábside central } \\
\text { Nicho para fuente en el ábside sur } \\
\text { Cortes en dovelas del arcosolio } \\
\text { Elemento vertical divisorio en el cuarto tramo de la fachada sur exterior } \\
\text { Huellas de elementos sobre el cuarto tramo de la fachada sur exterior } \\
\text { Huellas de elemento vertical sobre el cuarto tramo de la fachada sur exterior } \\
\text { Agujero en el cuarto tramo de la fachada sur exterior } \\
\text { Agujeros por encima del segundo forjado en el alzado norte exterior } \\
\text { Agujeros diferentes forjados en el alzado norte exterior } \\
\text { Huellas de elementos sobre la fachada oeste exterior }\end{array}$ & & $\begin{array}{l}100 \\
100 \\
103 \\
101 \\
101 \\
101 \\
101 \\
101 \\
101 \\
101\end{array}$ \\
\hline VI & $\begin{array}{l}109 \\
125 \\
127 \\
141 \\
142 \\
143 \\
144 \\
164 \\
165 \\
168 \\
169 \\
170 \\
176 \\
\\
178 \\
185 \\
186 \\
187 \\
\end{array}$ & $\begin{array}{l}\text { Desmonte y reconstrucción de las bóvedas del primer tramo y ábside de la nave } \\
\text { central } \\
\text { Tarima sobre rastreles y escombro de nivelación } \\
\text { Rozas en la fachada sur } \\
\text { Agujeros bajos } \\
\text { Varios agujeros en el tramo occidental de la nave central } \\
\text { Retalles horizontales en el tramo occidental de la nave central } \\
\text { Varios agujeros en el pilar entre el segundo y tercer tramo de la nave central } \\
\text { Reparación de los restos de la bóveda a los pies de la torres } \\
\text { Sillares perdidos } \\
\text { Reparación de diferentes estructuras del primer tramo de la nave sur } \\
\text { Cegados de los arcos entre ábsides y de la embocadura del sur } \\
\text { Reparación del arco de embocadura al ábside norte } \\
\text { Huellas de andamios para el desmonte y reconstrucción de las bóvedas del prime } \\
\text { tramo y ábside de la nave central } \\
\text { Agujeros en el frente del pilar entre ábside norte y central } \\
\text { Agujeros en diferentes pilares de la nave norte } \\
\text { Cortavientos } \\
\text { Hueco para la cuerda de la campana }\end{array}$ & $\begin{array}{l}128134 \\
166 \\
\\
\\
\end{array}$ & 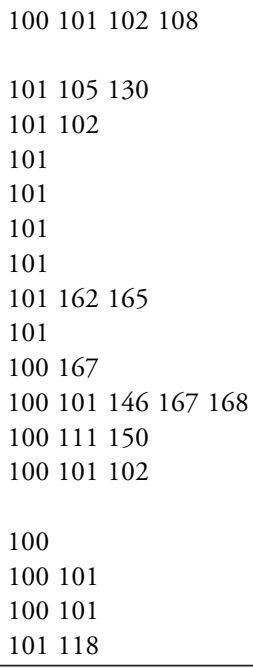 \\
\hline VII & $\begin{array}{l}110 \\
117 \\
119 \\
120 \\
121 \\
122 \\
126 \\
128 \\
\\
129 \\
133 \\
134 \\
166 \\
171 \\
172 \\
174 \\
175 \\
177 \\
180 \\
181 \\
182 \\
183 \\
184\end{array}$ & $\begin{array}{l}\text { Reparación del ábside sur } \\
\text { Desmonte de la capilla sur } \\
\text { Reparación de la fachada oeste } \\
\text { Reparación de la fachada sur occidental } \\
\text { Últimas reparaciones de la iglesia } \\
\text { Instalación eléctrica } \\
\text { Reparación del arcosolio extremo occidental fachada sur } \\
\text { Retejados } \\
\text { Escalones de la puerta norte } \\
\text { Huella de canalón al exterior del ábside central } \\
\text { Nuevas ventanas en primer tramo nave central } \\
\text { Inspecciones del subsuelo } \\
\text { Retablo del ábside norte } \\
\text { Picado enfoscados de la iglesia } \\
\text { Reparaciones de cemento en el interior de la iglesia } \\
\text { Sellado de un agujero con mortero blanco en el ábside central } \\
\text { Púlpito y tornavoz } \\
\text { Pintura plástica en el ábside sur } \\
\text { Reparaciones de los pilares entre el primer y segundo tramo } \\
\text { Reparación de imposta del cuarto tramo de la nave central } \\
\text { Erosión de zona inferior de diferentes pilares de la iglesia } \\
\text { Instalaciones varias }\end{array}$ & $\begin{array}{lll}128 & & \\
119 & 128 & 184 \\
121 & 128 & 129\end{array}$ & 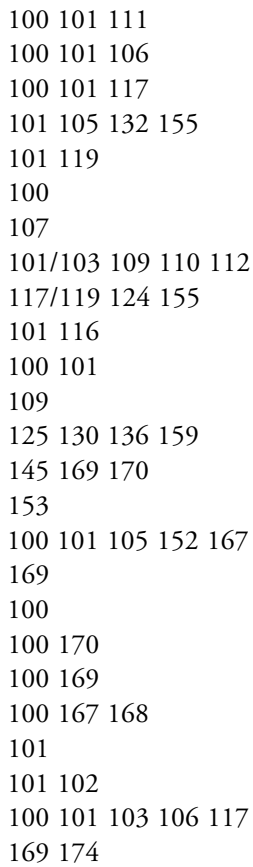 \\
\hline
\end{tabular}

